\title{
Advances in aptamer screening and aptasensors' detection of heavy metal ions
}

\author{
Wenfei Guo, Chuanxiang Zhang, Tingting Ma, Xueying Liu, Zhu Chen, Song Li* and Yan Deng*
}

\begin{abstract}
Heavy metal pollution has become more and more serious with industrial development and resource exploitation. Because heavy metal ions are difficult to be biodegraded, they accumulate in the human body and cause serious threat to human health. However, the conventional methods to detect heavy metal ions are more strictly to the requirements by detection equipment, sample pretreatment, experimental environment, etc. Aptasensor has the advantages of strong specificity, high sensitivity and simple preparation to detect small molecules, which provides a new direction platform in the detection of heavy metal ions. This paper reviews the selection of aptamers as target for heavy metal ions since the 21th century and aptasensors application for detection of heavy metal ions that were reported in the past five years. Firstly, the selection methods for aptamers with high specificity and high affinity are introduced. Construction methods and research progress on sensor based aptamers as recognition element are also introduced systematically. Finally, the challenges and future opportunities of aptasensors in detecting heavy metal ions are discussed.
\end{abstract}

Keywords: Aptamer, Screening, SELEX, Aptasensor, Heavy metals ion, Detection

\section{Background}

With development of industry and exploitation of resources, many heavy metal ions enter rivers and soil and cause serious pollution to the environment $[1,2]$. Heavy metal ions are difficult to be biodegraded and they can accumulate thousands of times in the human body under biological amplification action of food chain [3]. Moreover, heavy metal ions influence the activity of proteins and enzymes in the human body and accumulate in some organs, which causes chronic poisoning [4, 5]. The pollution of heavy metal ions is seriously harmful to human health, which has aroused great concern in the world [6]. Therefore, it is necessary to develop a rapid, sensitive and reliable method for trace detection of heavy metal ions.

*Correspondence: solisong@163.com; hndengyan@126.com Hunan Key Laboratory of Biomedical Nanomaterials and Devices, Hunan University of Technology, Zhuzhou 412007, China
The detection methods for heavy metal ions are various, including traditional methods and novel biosensors [7]. The traditional detection methods include atomic absorption/emission spectrometry, atomic fluorescence spectrometry, inductively coupled plasma mass spectrometry, high performance liquid chromatography and so on [8-12]. These methods can accurately quantify heavy metal ions with high sensitivity but they require professionals for on-site and routine environmental monitoring, and sample pretreatment is complex with expensive equipment, which limits their application [13]. As a novel detection tool, biosensor depends on specific recognition elements such as enzymes/substrates, antigens/ antibodies and targets/aptamers [14]. However, enzyme biosensors are sensitive to $\mathrm{pH}$, temperature, pressure and ultraviolet irradiation, and most antibodies are obtained from live animals, which makes them difficult to obtain and expensive to test $[15,16]$. Because functional nucleic acid is easy to identify and modify, it is a powerful tool to construct sensor for heavy metal ions detection $[17,18]$.

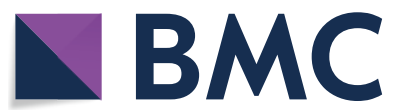

(c) The Author(s) 2021. This article is licensed under a Creative Commons Attribution 4.0 International License, which permits use, sharing, adaptation, distribution and reproduction in any medium or format, as long as you give appropriate credit to the original author(s) and the source, provide a link to the Creative Commons licence, and indicate if changes were made. The images or other third party material in this article are included in the article's Creative Commons licence, unless indicated otherwise in a credit line to the material. If material is not included in the article's Creative Commons licence and your intended use is not permitted by statutory regulation or exceeds the permitted use, you will need to obtain permission directly from the copyright holder. To view a copy of this licence, visit http://creativecommons.org/licenses/by/4.0/. The Creative Commons Public Domain Dedication waiver (http://creativecommons.org/publicdomain/zero/1.0/) applies to the data made available in this article, unless otherwise stated in a credit line to the data. 
Aptamers, also known as artificial antibodies, are single-stranded deoxyribonucleic acid (ssDNA) or ribonucleic acid (RNA) obtained by SELEX (Systematic Evolution of Ligands by Exponential Enrichment) method $[19,20]$. Compared with traditional antibodies, aptamers have the advantages of simple preparation, good stability and easy labeling, and higher specificity and affinity to targets [21]. Since 1990, aptamers have been widely used in the detection of cells, viruses, proteins, sugars, antibodies and pesticides [22-24]. However, metal ions have great challenges in aptamer selection and aptamer-based sensor (aptasensor) construction because of their small molecular weight and single binding site $[25,26]$. The application of functional nucleic acids as metal aptamers has been studied for 25 years [27]. At present, heavy metal ions, especially $\mathrm{Pb}^{2+}, \mathrm{Cd}^{2+}$ and $\mathrm{Hg}^{+}$, are widely used detection targets in aptasensors [28], and the common aptamer sensors include optical aptasensors and electrochemical aptasensors, which show wide range of applications [29, 30]. How to select aptamers with high affinity and construct aptamer sensors for rapid and sensitive detection of heavy metal ions has become a longterm research topic [31-33].

This paper therefore reviews the aptamer selection methods and aptamer sensors construction for detection of heavy metal ions in the past five years, and provides reference for development of aptamer sensors in the research field of heavy metal ions detection.

\section{Selection of heavy metal ion aptamers}

The basic process for SELEX is shown in Fig. 1. The oligonucleotide library is characterized by fixed sequences at both ends and random sequences in the middle of the oligonucleotides [34]. The fixed sequence contains the binding site for primers related to PCR amplification. The random sequence generally contains 30-60 nucleotides which determine different spatial structure for each nucleic acid molecule and ensures the diversity of the library [35]. The SELEX process is mainly repeated in the following four steps: binding, separation, amplification and purification [36]. Oligonucleotides with high affinity to the target are separated from a large of random library, and the purity increases via SELEX process [37]. After multiple cycles of SELEX process, the enrichment of DNA library is monitored to determine the number of cycles that terminate the process [38]. The experimenters further clone and sequence the fragment of SELEX, and then analyze their secondary structure and determine affinity, which finally obtain specific aptamer [39].

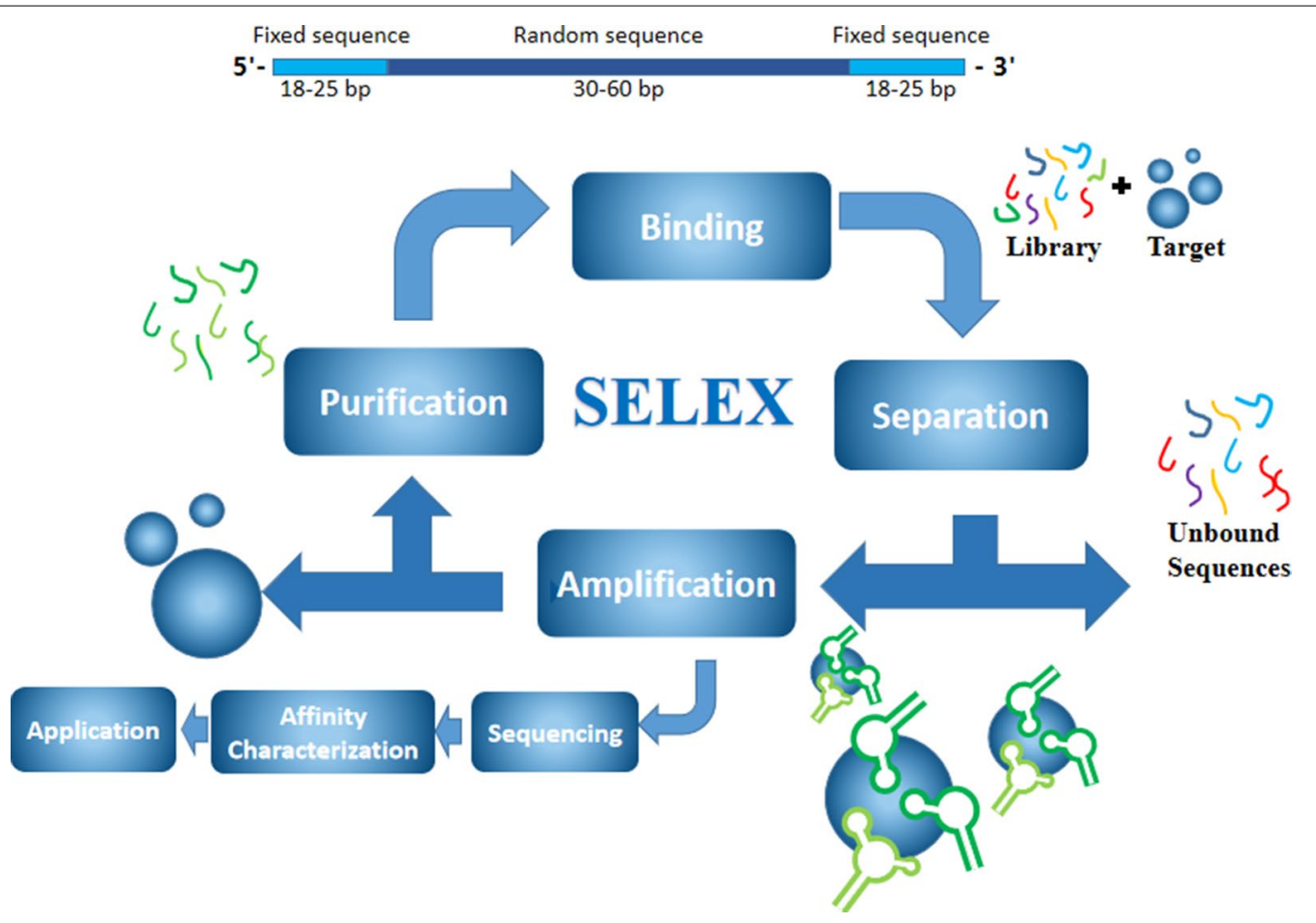

Fig. 1 A schematic diagram of SELEX. The initial library contains about $10^{14}-10^{16}$ random oligonucleotides, which is composed of fixed primer sequences with 18-25 bp at both ends and 30-60 bp in the middle. The aptamer is obtained after several rounds of selection, including binding, separation, amplification and purification, and the products are used in the next round of selection 
Compared with other targets, heavy metal ions have the following advantages and challenges. Aptamer, a kind of polyanion, can attract metal ions by electrostatic interaction [40]. Different aptamer sequences can constitute different three-dimensional structures which have affinities for certain metal ions [41]. Because of simple structure and single binding site for heavy metal ions, the aptamers lack effective recognition sites [42]. Similar structures of different metal ions also make it difficult for aptamers to specifically recognize metal ions in the same group. Moreover, there are challenges in the selection of heavy metal ion aptamers. Heavy metal ions have small molecular weight and small steric hindrance after binding to nucleotide sequence, which will seriously affect their separation in the screening process. Most SELEX methods are difficult to effectively separate highly specific aptamers. Since 1995, Ciesiolka and his colleagues have obtained aptamers of $\mathrm{Zn}^{2+}$ by affinity chromatography, extending the target for aptamers to the field of heavy metal ions [43]. Nowadays, the common selection principle for heavy metal ions is to fix the library on the matrix, which includes affinity chromatography-SELEX and Graphene oxide-SELEX [44].

\section{Affinity chromatography-SELEX}

Affinity chromatography-SELEX was first used to select aptamers for organic dyes by Ellington in 1990 [45]. When screening heavy metal ions, agarose or resin is usually filled into the chromatographic column as a solid matrix, and the random library is fixed on the solid substrate under the action of streptavidin-biotin [46]. Heavy metal ions were injected into the affinity chromatography column as mobile phase to incubate and some specific nucleic acid sequences are highly attractive to the target via affinity interaction $[47,48]$. The difficulty incubation was improved by reducing the target concentration, and the aptamer with high affinity was obtained [49]. Affinity chromatography has been widely applied to select aptamers for heavy metal ions. Rajendran and Ellington [50] obtained $\mathrm{Zn}^{2+}$-specific aptamer beacon by affinity chromatography. The ssDNA sequence was immobilized on the affinity chromatography column and the aptamer was selected by $\mathrm{Zn}^{2+}$ solution. From the fourth round, other transition metal ions except zinc were added to negative selection and the Kd was $15 \mu \mathrm{M}$ after 12 rounds of selection. Wang et al. [51] used the same selection method for target-induced strands release to obtain the $\mathrm{Cd}^{2+}$ aptamer $\mathrm{Cd}-2-1$ with high specificity. The conformation of aptamer changes when it binds to $\mathrm{Cd}^{2+}$, which shows obvious change on Circular Dichroism (CD) spectral. Chen et al. [52] also used the same method to select aptamers for $\mathrm{Pb}^{2+}$. The aptamer $\mathrm{Pb}-14 \mathrm{~s}$ with $\mathrm{Kd}$ of $0.76 \pm 0.18 \mu \mathrm{M}$ was obtained after 14 rounds of positive selection and 4 rounds of negative selection. Wu et al. [53] used $\mathrm{Cd}^{2+}$ as the target and obtained the aptamer with $\mathrm{Kd}$ of $34.5 \mathrm{nM}$ after 11 rounds of positive and negative selection, which was rich in $\mathrm{T}$ and $\mathrm{G}$.

Similar to agarose, resin is also an important material for affinity chromatography. Kim et al. [54] established a method for aptamers selection in vitro with an affinity column immobilized arsenic on Affi-Gel 10 resin. The Kd of Ars-3 to detect As (V) and As (III) was $4.95 \pm 0.31$ and 7.05 $\pm 0.91 \mathrm{nM}$. Moreover, Wrzesinskid and Ciesiolka [55] immobilized the RNA library on NTA resin and eluted the library with $\mathrm{CoCl}_{2}$ solution. After 15 rounds of selection, the $\mathrm{Co}^{2+}$ aptamer with $\mathrm{Kd}$ of $1.1 \pm 0.15 \mathrm{mM}$ was obtained. Subsequently, they identified the binding sites by $\mathrm{Co}^{2+}$-induced cleavage and speculated the chemical properties, such as hardness and coordination structure of metal ions, were important factors affecting aptamers in selection of heavy metal ions.

\section{Graphene oxide-SELEX}

Graphene oxide (GO) is a common separation medium and SELEX based on GO is a common screening method [56]. Using the hydrophobic interaction with base, GO can adsorb ssDNA on surface by $\pi-\pi$ stacking [57]. For example, Cho et al. [58] established a method for selecting aptamers by graphene oxide-adsorbed nanoparticles. The aptamer DNA01 of palladium ions was obtained with $\mathrm{Kd}$ of $4.6 \pm 1.17 \mu \mathrm{M}$ after 13 rounds of selection.

\section{Others}

Nitrocellulose filter-SELEX is an in vitro aptamer selection method based on nitrocellulose filter with certain pore size [59]. The pore size of nitrocellulose filter can intercept the nucleic acid sequence that binds to the target, and the other nucleic acid sequence without binding to the target were separated [60]. The target is separated from the nucleic acid sequence by changing the nucleic acid solution environment, and then eluted from the nitrocellulose filter [61]. Tuerk and Gold [62] used nitrocellulose filter-SELEX method 30 years ago to select aptamers from $\mathrm{T}_{4}$ DNA phages and the aptamer quickly became a research hotspot. Kawakami et al. [63] selected aptamers with zinc in vitro, and then isolated and obtained $\mathrm{Zn}^{2+}$-dependent aptamers which novel novel RNA molecules in HIV-1Tat protein.

Circular dichroism (CD) is very sensitive to secondary structure of nucleic acid [64]. The spectral shape and signal of CD can effectively show the secondary structure changes of DNA caused by the binding to small molecules [65]. Isothermal titration calorimetry (ITC) is an intuitive and unlabeled method for analyzing and characterizing molecules which can directly measure the thermal changes caused by the chemical reactions between 
the two components [66, 67]. Therefore, CD and ITC can accurately monitor the binding between aptamer and target. $\mathrm{Li}$ and $\mathrm{Ran}$ [68] selected $\mathrm{Cd}^{2+}$ aptamer called issAP08-Cd ${ }^{2+}$ with $\mathrm{Kd}$ of $2.9 \mu \mathrm{M}$ via ITC. Moreover, Ran et al. [69] selected the $\mathrm{Pb}^{2+}$ aptamer with $\mathrm{Kd}$ of $1.13 \mu \mathrm{M}$ via $C D$ and ITC, which was named iss AP17-Pb ${ }^{2+}$.

Structure-switching particle display (SS-PD) is a novel method to produce high-quality structure-switching DNA aptamers in vitro [70]. When the sequence is bound to the target, the conformational change becomes large. The combination between each nucleic acid fragment and heavy metal ions is directly measured by fluorescence-activated cell sorting, and only the aptamers with the highest affinity are isolated. This method does not need any labeling or chemical modification, and the aptamers with high affinity can be separated in a short period of time. Qu et al. [71] used this method to obtain aptamers of $\mathrm{Hg}^{2+}$ and $\mathrm{Cu}^{2+}$ (Fig. 2).

Molecular dynamics (MD) simulation is a recently reported new aptamer selection method that can provide information such as orientation, folding-unfolding pathway and conformational rearrangement of aptamer, location of binding sites and availability of target sites [72]. This method modifies or mutates the existing sequence by examining the aptamer-target interaction to produce a new sequence with higher affinity. Khoshbin et al. [73] used this method to select the aptamers from $\mathrm{Pb}^{2+}$ and obtained the aptamer M4-16 with highest specificity.

The aptamers of heavy metals are difficult to screen, and the related reviews have not been reported. Table 1 shows the aptamer sequences of all heavy metals mentioned in this chapter.

\section{Aptasensors for heavy metals ion detection}

Compared with other targets, the simple structure and single binding site for heavy metal ions increase the difficulty for aptamer recognition [74]. The combination between heavy metal ions and aptamers will not occur with obvious mass change and steric hindrance effect [75]. This combination limits the application and sensitivity of many aptasensors. Although it is difficult to construct aptasensors for heavy metal ions detection, compared with traditional methods for detection of heavy metal ions, the aptasensor still has the advantages of high sensitivity and fast reaction speed [76]. This chapter introduces efficient methods for using aptamer sensora to detect heavy metal ions in the past five years.

\section{Optical aptasensors}

Optical aptasensor is an important method for detection of heavy metal ions, including fluorescence aptasensor, colorimetric aptasensor, surface plasmon resonance (SPR) aptasensor, surface enhanced Raman scattering (SERS) aptasensor, fluorescence resonance energy transfer (FRET) aptasensor, chemiluminescence (CL) aptasensor and electrochemiluminescence (ECL) aptasensor [77-81]. In this chapter, the mechanism for the binding between aptamer and heavy metal ions is analyzed, and the application of above optical sensors to detect heavy metal ions is reviewed.

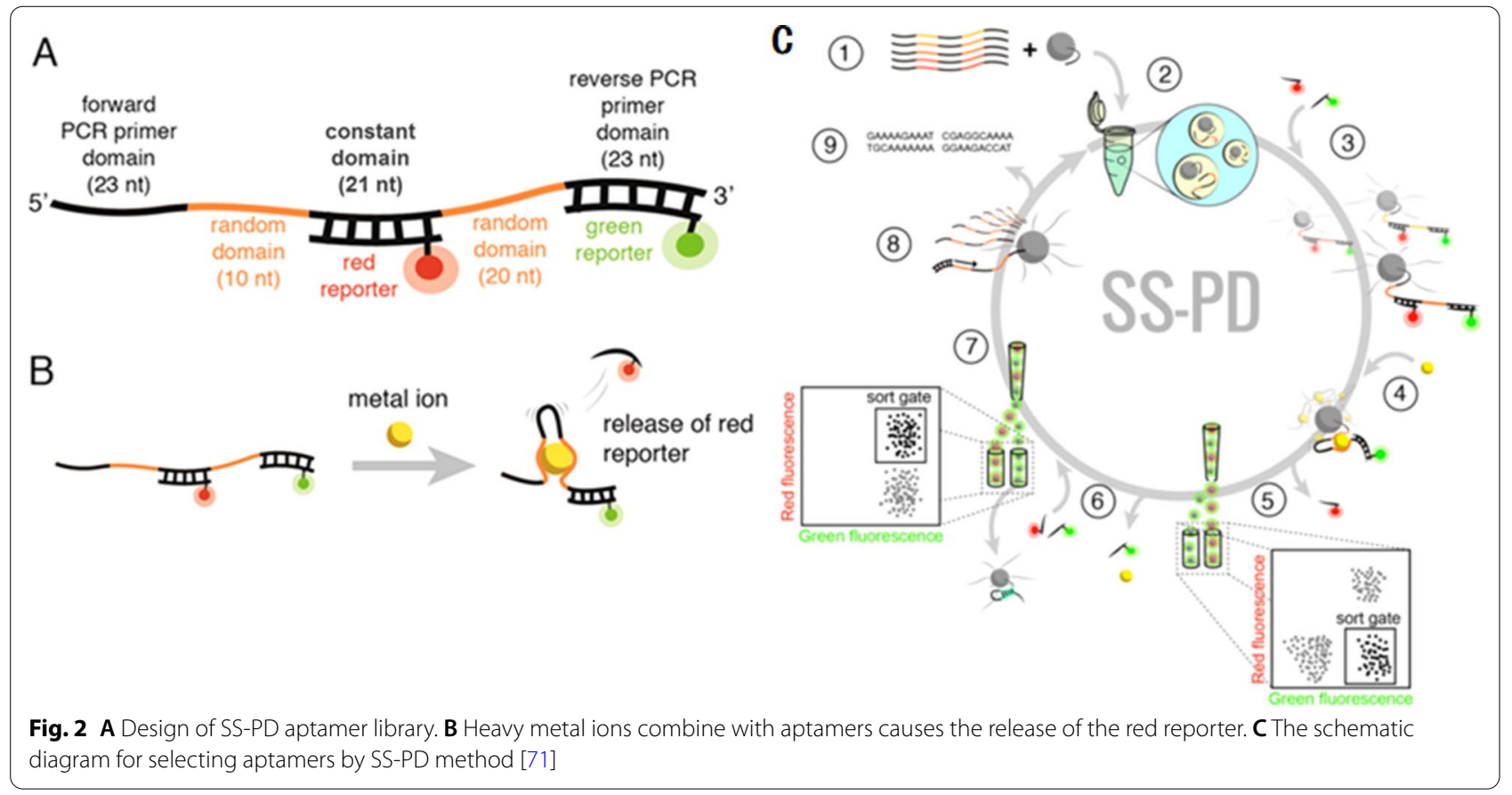


Table 1 All the reports on the aptamers of heavy metal ions since the 21th century

\begin{tabular}{|c|c|c|c|c|c|c|}
\hline Target & Name & Method & Cycle & Kd & Sequence & Refs \\
\hline $\mathrm{As}^{3+}$ & Ars-3 & Affinity Chromatography & 10 & $7.05 \pm 0.91 \mathrm{nM}$ & TTACA GAACA ACCAA CGTCG CTCCG GGTAC TTCTT CATCG & [54] \\
\hline $\mathrm{As}^{3+}$ & Ars-7 & Affinity Chromatography & 10 & $13.0 \pm 1.25 \mathrm{nM}$ & ATGCA AACCC TTAAG AAAGT GGTCG TCCAA AAAAC CATTG & [54] \\
\hline $\mathrm{Cd}^{2+}$ & $\mathrm{Cd}-4$ & Affinity Chromatography & 11 & $34.5 \mathrm{nM}$ & GGACT GTTGT GGTATTATTTTTTGGTTGTGC & [53] \\
\hline $\mathrm{Cd}^{2+}$ & $\mathrm{CD}-2-2$ & Affinity Chromatography & 14 & / & CTCAG GACGA CGGGTTCACA GTCCG TTGTC & [51] \\
\hline $\mathrm{Pb}^{2+}$ & $\mathrm{Pb}-14 \mathrm{~s}$ & Affinity Chromatography & 18 & $0.76 \pm 0.18 \mu \mathrm{M}$ & GACGA CGGCC AGTAG CTGAC ATCAG TGTAC GATCT AGTCG TC & [52] \\
\hline $\mathrm{Pb}^{2+}$ & M4-16 & molecular dynamics & & / & GGGA GGGT GGGT GGGA & [73] \\
\hline $\mathrm{Zn}^{2+}$ & $\mathrm{Zn}-6 \mathrm{~m} 2$ & Affinity Chromatography & 12 & $15 \mu \mathrm{M}$ & $\begin{array}{l}\text { GCATC AGTTA GTCAT TACGC TTACG GCCCG ATCCT AACTT GCTAC } \\
\text { TGTCC CCTTC CGCCA GTTGT GCCGC GATTG TGAAG TCGTG TCCC }\end{array}$ & {$[50]$} \\
\hline $\mathrm{Co}^{2+}$ & NO.20 & Affinity Chromatography & 15 & $1.1 \pm 0.15 \mathrm{mM}$ & 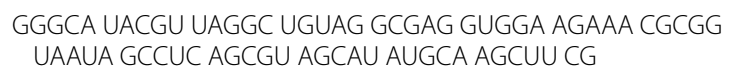 & [55] \\
\hline $\mathrm{Pd}^{2+}$ & DNA 01 & GO & 13 & $4.6 \pm 1.17 \mu \mathrm{M}$ & GGGCG GACGC TAGGT GGTGA TGCTG TGCTA CACGT GTTGT & [58] \\
\hline $\mathrm{Hg}^{2+}$ & SSA-Hg $\|$ & SS-PD & 4 & $2.27 \pm 0.76 \mu \mathrm{M}$ & $\begin{array}{l}\text { TCCAA GCTCTTTTCT GCAGC TATTC TTGTT TCGAA ACTTG CTAAG } \\
\text { CTGCG T }\end{array}$ & [71] \\
\hline $\mathrm{Cu}^{2+}$ & SSA-Cu II & SS-PD & 4 & $47.15 \pm 22.16 \mu \mathrm{M}$ & $\begin{array}{l}\text { ATCGC GATATTTTCT GTAGC GATTC TTGTTTGAGC GCTCG GTACG } \\
\text { AACAG A }\end{array}$ & \\
\hline
\end{tabular}

\section{Lead}

Lead is a heavy metal element with its ions $\left(\mathrm{Pb}^{2+}\right)$ seriously endangering human health. The concentration of lead ions in the human body reaches a certain level, that it will cause cognitive and motor impairments, especially affecting the growth and intellectual development of children [82]. It was found in another study that $\mathrm{Pb}^{2+}$ can induce the folding of DNA structure [83]. Thrombin binding aptamer (TBA) is a ssDNA sequence rich in guanine, which contains $5^{\prime}$-GGTTGGTGTGGTTGG$3^{\prime}$ [84] chain. Under the action of $\mathrm{Pb}^{2+}$, TBA folds into a G-quadruplex structure. Many researchers fabricated aptasensors to detect $\mathrm{Pb}^{2+}$ using this aptamer. For example, a novel aptasensor based on FRET was reported for detection of $\mathrm{Pb}^{2+}$ in contaminated water by using Upconversion nanoparticles (UCNPs) as donor and gold nanoparticles (AuNPs) as acceptors [85]. The ssDNA sequence for the modified UCNPs was 5'-AAGGGTGGGTGG GT-3', which could be folded into a G-quadruplex structure in the presence of $\mathrm{Pb}^{2+}$. When the conformation of aptamer was changed, the molecular distance between energy donor and acceptor also changed, and the green fluorescence for UCNPs was quenched. The concentration of $\mathrm{Pb}^{2+}$ was detected by fluorescence recovery, and the detection limit was as low as $4.1 \mathrm{nM}$. Colorimetric aptasensor can observe the color change through the naked eyes or spectrophotometer to realize the quantitative and qualitative detection of the target. Ouyang et al. [86] designed a SERS aptasensor based on gold nanoparticles (GNP) with nanoplasmonic SERS at $1614 \mathrm{~cm}^{-1}$. The $\mathrm{Pb}^{2+}$ aptamers were adsorbed on the surface of the AuNPs inhibited the its nonacatalysis and resulted in the decreased redox product for GNP nanoplasmonic effect. The aptamer formed a stable G-quadruplex in the presence of $\mathrm{Pb}^{2+}$ by binding to it, releasing free AuNPs and enhanced SERS signal. Tao et al. [87] developed a colorimetric aptasensor based on graphene/Fe3O4AuNPs composites for monitoring $\mathrm{Pb}^{2+}$. The complementary aptamer chain competed with metal ions to bind aptamer. The aptamer bonded the target to form G-quadruplex when $\mathrm{Pb}^{2+}$ was added. Moreover, the free cDNA inhibited the catalytic activity adsorbed onto the surface of the graphene/Fe3O4-AuNPs composites. The aptasensor showed that absorbance of the reaction solution at $652 \mathrm{~nm}$ and concentration of $\mathrm{Pb}^{2+}$ had good linear correlation over the range of $1-300 \mathrm{ng} / \mathrm{mL}$. Wu et al. [88] designed an aptasensor based on double fluorescent dye by using the same aptamer sequence. The synergistic application of two different dyes provided built-in correction for environmental conditions and improved the stability and accuracy while maintaining specificity. Ma et al. [89] also established a colorimetric aptasensor to detect trace lead ions by silver staining and $\mathrm{Pb}^{2+}$ aptamer of G-rich sequences [90].

The aptasensors for detection of $\mathrm{Pb}^{2+}$ using G-rich oligonucleotides as recognition elements have high selectivity, and researchers have improved the sensitivity of $\mathrm{Pb}^{2+}$ detection by amplifying the detection signal. For example, et al. [91] introduced an aptasensor based on quartz crystal microbalance (QCM), which amplified the frequency change by using oligonucleotide modified AuNPs to enhance its responsiveness. The aptamer immobilized on the surface of QCM combined with $\mathrm{Pb}^{2+}$ to prevent self-assembly of AuNPs on QCM. The trace concentration of QCM was determined by monitoring the change of $\mathrm{Pb}^{2+}$ response frequency. This sensor could detect $\mathrm{Pb}^{2+}$ in the range of 5-200 $\mathrm{nM}$ and detection limit was as low as $4 \mathrm{nM}$. 
Chen et al. [52] in another study obtained the aptamer $\mathrm{Pb}-14 \mathrm{~S}$ by SELEX method with good specificity and high affinity, and constructed a fluorescent aptasensor for detection of $\mathrm{Pb}^{2+}$ based on complex with $\mathrm{Pb}^{2+}$-induced release of fluorescence-labeled aptamer $\mathrm{Pb}-14 \mathrm{~S}$ and a quencher-labeled short complementary sequence. The $\mathrm{Pb}-14 \mathrm{~S}$ accurately identified $\mathrm{Pb}^{2+}$ and eliminated the interference of other metal ions with similar structure. The aptamer was transformed into stem-ring structure with addition of $\mathrm{Pb}^{2+}$ and the distance between fluorescent agent and quenching agent was changed, and the fluorescence intensity also changed. Moreover, the fluorescence intensity enhanced with $\mathrm{Pb}^{2+}$ concentration increased, which had a detection linear correlation in the range of 100 to $1000 \mathrm{nM}$. Aptamers with higher affinity need to be combined in future research with more effective signal amplification strategies to improve the sensor's sensitivity.

\section{Mercury}

Mercury is one of the harmful water pollutions that can accumulate in the human body and damage the kidneys and capillaries [92, 93]. Kosturko et al. [94] proposed the crystal structure of 2:1 complex of 1-methylthymine$\mathrm{Hg}^{2+}$ in 1974. This theory was put forward earlier than the concept of aptamer for 16 years, and it has become the most commonly used method for aptasensor based detection of $\mathrm{Hg}^{2+}$. Qi et al. [95] constructed a chemiluminescence aptasensor for the detection of $\mathrm{Hg}^{2+}$, where the recognition element was an aptamer with a sequence of $5^{\prime}$-TTT TTT TTT T- $3^{\prime}$. Aptamer is a kind of polyanion that binds to $(+)$ AuNPs to inhibit the luminescence of $\mathrm{H}_{2} \mathrm{O}_{2}+$ Luminol system in the absence of $\mathrm{Hg}^{2+}$, which combines with aptamers to form T-Hg-T complex after addition of the target. (+)AuNPs charge effect aptamer conformation change induced by $\mathrm{Hg}^{2+}$ effectively amplified luminescence of $\mathrm{H}_{2} \mathrm{O}_{2}+$ Luminol system. The low detection limit for this sensor to detect $\mathrm{Hg}^{2+}$ concentration was $16 \mathrm{pM}$. This group used the same $\mathrm{Hg}^{2+}$ aptamer and signal amplification strategy to design a colorimetric aptasensor with detection limit of $49 \mathrm{pM}$ [96]. Wang et al. [97] moreover found that ssDNA bound a mixedvalence state cerium-based metal-organic framework (MVC-MOF), shielding its active sites and inhibiting its oxidase-like activity, while dsDNA activated its catalytic activity. In addition to $\mathrm{Hg}(\mathrm{II})$, the ion was bound to thymine-rich ssDNA (T-ssDNA) as a model DNA that caused formation of T-dsDNA if dsDNA was added. Hence, a colorimetric sensor to detect $\mathrm{Hg}^{2+}$ in water samples was designed. The aptamer bound with $\mathrm{Hg}^{2+}$ to produce heteroduplex and impaired the activity of mimicking the oxidase. The oxidase substrate $3,3^{\prime}, 5,5^{\prime}$-tetramethylbenzidine generates colored products under aerobic conditions, and the detection limit for $\mathrm{Hg}^{2+}$ was $10.5 \mathrm{nM}$. Wu et al. [98] designed an aptasensor based on G-quadruplex structure switching and $\mathrm{T}-\mathrm{Hg}^{2+}-\mathrm{T}$ mismatch pair, and amplified the signal with two kinds of fluorescent dyes. Caglayan [99] applied SPR in another study to detect $\mathrm{Hg}^{2+}$ and made a SPR aptasensor with a detection limit of $26 \mathrm{pM}$.

Except for the self-folding of T-rich aptamers, $\mathrm{T}-\mathrm{Hg}^{2+}$ $\mathrm{T}$ double-strands can be formed by artificially designing ssDNA that is partially complementary to aptamers. Sun et al. [100] for example introduced a fluorescent assay based on formation of $\mathrm{T}-\mathrm{Hg}^{2+}-\mathrm{T}$ base pairs and aptamers-functionalized magnetic beads (AMB) for $\mathrm{Hg}^{2+}$. When the target was absent, the signal transduction probe (STP) could bind to the aptamer through complementary base pairing. After magnetic separation, the fluorescence signal was quite week owing to lack of STP in the detection solution. Help DNA competitively combined with AMB in presence of $\mathrm{Hg}^{2+}$, and caused formation of T-Hg-T base pairs. Moreover, STP was left in the detection solution after magnetic separation and fluorescence signal was significantly increased. The fluorescence intensity and $\mathrm{Hg}^{2+}$ concentration had good linear correlation in the range of $2-160 \mathrm{n}$ and detection limit was $0.2 \mathrm{nM}$. Shi et al. [101] developed a FRET aptasensor based on $\mathrm{T}-\mathrm{Hg}^{2+}-\mathrm{T}$ double-stranded structure. The aptamer-modified Copper @ Gold nanoclusters (apt$\mathrm{Cu} @ \mathrm{Au} \mathrm{NCs}$ ) aggregated in the solution in the presence of $\mathrm{Hg}^{2+}$, resulting in change of fluorescence intensity. Determined by fluorescence analysis, the $\mathrm{Hg}^{2+}$ detection limit for the sensor was $4.92 \mathrm{nM}$.

\section{Cadmium}

Cadmium has high toxicity. Food and water contaminated by cadmium do serious harm to the human body, and its metabolism is slow in the human body [102]. Cadmium accumulates in the human body, leading to the decline of lung function and renal failure. The development of simple and sensitive methods for rapid detection of cadmium ions $\left(\mathrm{Cd}^{2+}\right)$ is therefore of significant importance [103]. In recent years, there have been many reports about $\mathrm{Cd}^{2+}$ aptasensors on detection of $\mathrm{Cd}^{2+}$. For example, Xue et al. [104] proposed the $\mathrm{Cd}^{2+}$ concentration-dependent interaction mechanism and conformation of aptamer by dual polarization interferometry (DPI) (Fig. 3). Under the action of low concentration of $\mathrm{Cd}^{2+}$, $\mathrm{Cd}^{2+}$ mainly interacted with phosphate groups from DNA to form extended ssDNA. The $\mathrm{Cd}^{2+}$ were bound with bases on the aptamer in the condition of high concentration of $\mathrm{Cd}^{2+}$, resulting in a tight and short hairpin structure through coordination interaction.

Gan et al. [105] designed a colorimetric sensor based on Cd-4 aptamer-functionalized AuNPs for $\mathrm{Cd}^{2+}$ detection. 

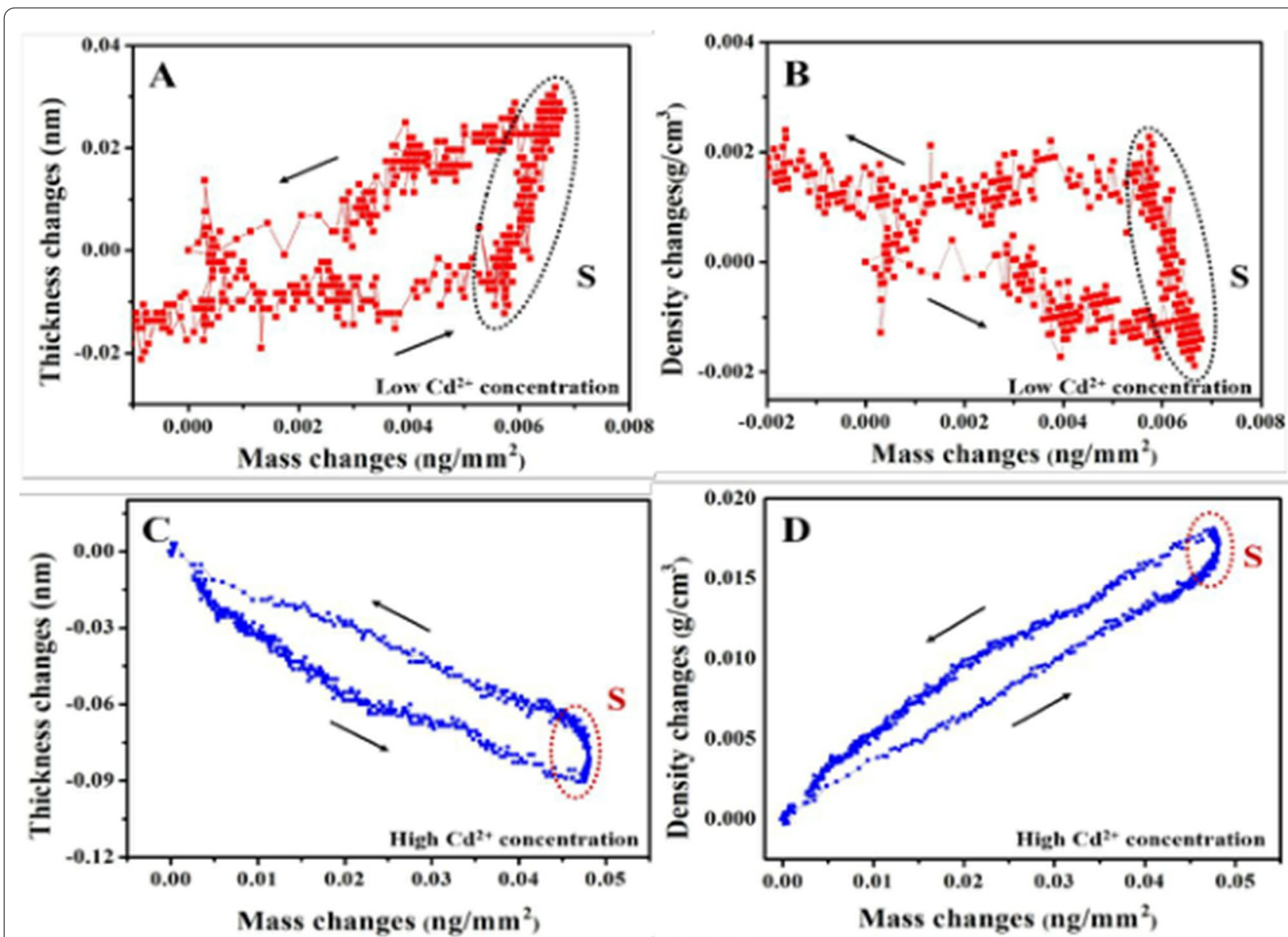

Fig. 3 A, B At low concentration of $\mathrm{Cd}^{2+}$, the thickness increases and the density decreases with the increase of mass load. It is speculated that the binding of $\mathrm{Cd}^{2+}$ to aptamer is mainly through the binding of phosphate group. C, $\mathbf{D}$ At high concentration of $\mathrm{Cd}^{2+}$, the thickness decreases and density increases with increased load. It is speculated that $\mathrm{Cd}^{2+}$ leads to the conformational transformation of DNA through the $\pi-\pi$ stacking of bases [104]

Aptamers could enhance the stability of AuNPs and avoid aggregation in high-salt solutions. The reason was that high-salt could shield the electrostatic repulsion among AuNPs and AuNPs aggregated when no aptamer was shrouded on the surface of AuNPs [106]. Free aptamers were reduced owing to the specific interaction between aptamers and $\mathrm{Cd}^{2+}$ when $\mathrm{Cd}^{2+}$ was added, which weakened the stability of AuNPs, resulting in AuNPs aggregation and strengthening ofsolution color. Zhu et al. [107] also designed a fluorescence sensor with a detection limit of $2.15 \mathrm{nM}$ for $\mathrm{Cd}^{2+}$ by using Cd-4 aptamers. The 6-carboxyfluorescein (6-FAM) and GGGG sequences were modified at both ends of the Cd-4 aptamer, which could change the conformation after binding with $\mathrm{Cd}^{2+}$. G4 is close to 6-FAM and photoinduced electron transfer, which results in fluorescence quenching. Zeng et al. [108] reported a personal glucose meter based on Cd-4 aptamer for detection of $\mathrm{Cd}^{2+}$. The signal amplification process triggered specific recognition between the aptamer and $\mathrm{Cd}^{2+}$ by exonuclease III, which is an invertase conjugated complementary single-stranded DNA. The direct conversion was established between $\mathrm{Cd}^{2+}$ concentration and glucose amount by means of invertase conjugates hydrolyzing sucrose into glucose, and the sensor could detect $\mathrm{Cd}^{2+}$ at as low as $5 \mathrm{pM}$.

\section{Other heavy metals}

Arsenic is globally recognized carcinogen that is widely contaminated in groundwater due to the influence of human industry and mining [109]. $\mathrm{As}^{3+}$ is the most toxic form, with its toxicity about 60 times of $\mathrm{As}^{5+}$. Ars-3 aptamer for specific recognition of $\mathrm{As}^{3+}$ was obtained in 2009 and it's for $\mathrm{As}^{3+}$ was $7.05 \pm 0.91 \mathrm{nM}$. Ars-3 aptamer has been widely used in the construction of $\mathrm{As}^{3+}$ aptasensors. Siddiqui et al. [110] designed a colorimetric aptasensor based on aptamer Ars-3-AuNPs. This first reported device included extraction, purification and 
detection of $\mathrm{As}^{3+}$ from field soil. The extracted and purified samples effectively eliminated the effects of other interfering ions and organic acids. Ars-3 could effectively capture $\mathrm{As}^{3+}$ and induced AuNPs aggregation. The smartphone-based measurement system measured $\mathrm{As}^{3+}$ content in the field in only three hours, with detection limit of $1.97 \mathrm{ppm}$.

The aptamer sensor combined with effective signal amplification strategy can improve the sensitivity of the aptasensor. Nguyen et al. [111] studied a colorimetric aptasensor with improved sensitivity for detection of $\mathrm{As}^{3+}$ based on the synergistic molecular assembly of Ars- 3 and cetyltrimethyl ammonium bromide (CTAB) on AuNPs. Using CTAB as binder could induce the aggregation of $\mathrm{As}^{3+}$ and Ars-3 aptamer-AuNPs, which resulted in visible color change. The detection limit for the prepared sensor was $16.9 \mathrm{ppb}$. Moreover, Zeng et al. [112] designed a fluorescence aptasensor based on continuous signal amplification strategy triggered by the target detection of $\mathrm{As}^{3+}$. The Ars-3 aptamer specially recognized
$\mathrm{As}^{3+}{ }^{3+}$ leading to the release of blocking DNA and triggering the subsequent signal amplification step. The sensor system produced a large number of $\mathrm{Mg}^{2+}$-dependent DNAzyme as the amplifier using Exonuclease III (Exo III)-mediated DNA cycle digestion. After magnetic separation, the active DNAzymes would continually catalyze and cleave substrate strands modified with fluorophore and quencher, thus a fluorescence signal for detection target was yielded and significantly amplified. The sensor system showed ultrasensitivity for detection of trace amount of $\mathrm{As}^{3+}$ owing to the synergetic signal amplification effect of EXO III and DNAzyme, and the detection limit was as low as $2 \mathrm{pM}$. Figure 4 demonstrates the response strength, correlation, signal amplification and specificity of the sensor to the target.

Apart from the widely used Ars-3, there are many reports on the use of other aptamers to construct $\mathrm{As}^{3+}$ detection sensors in recent years. Zhang et al. [113] established a SPR aptasensor for the determination of arsenic ion based on excellent catalytic
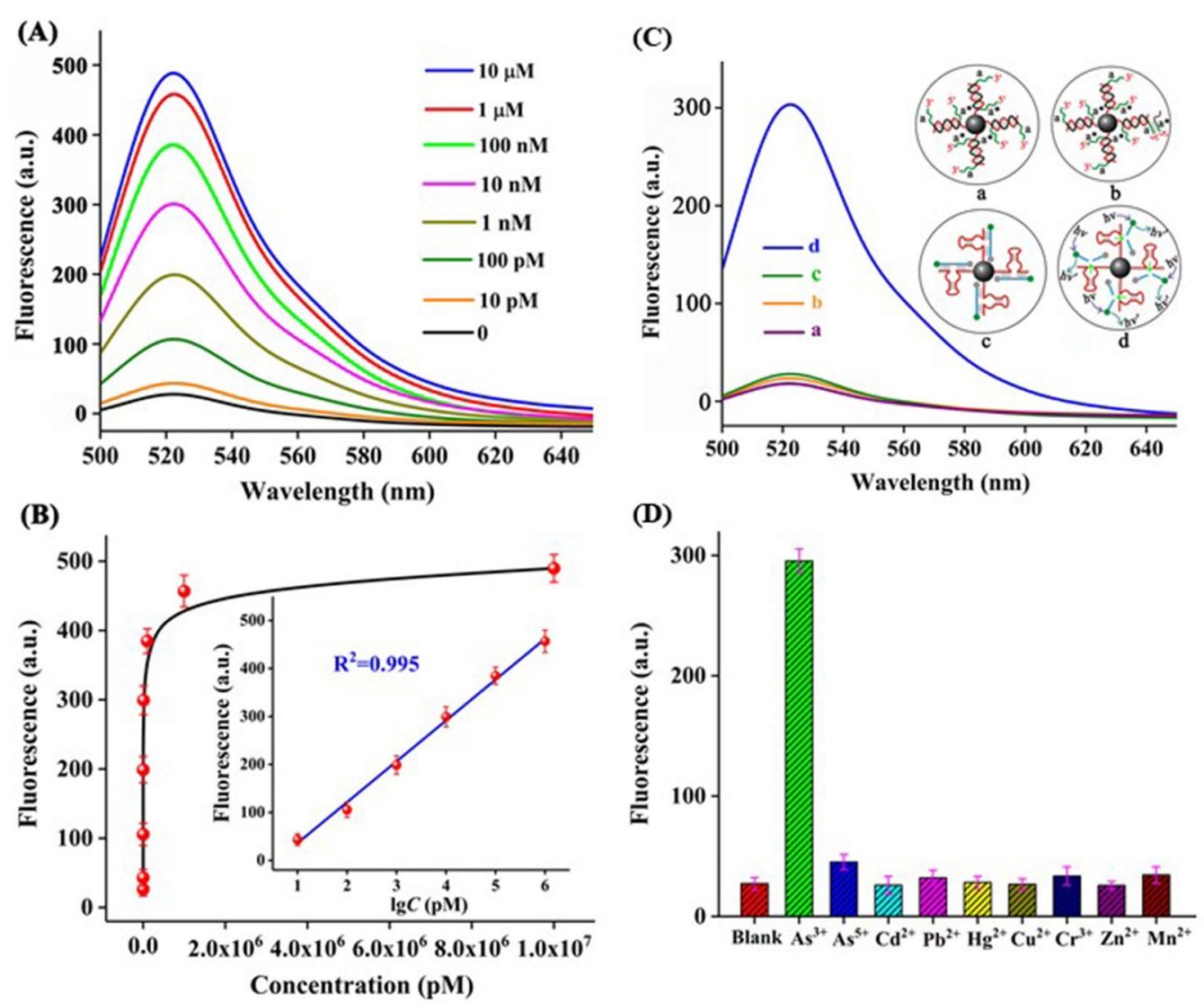

Fig. 4 A The fluorescence intensity of the sensor at different $\mathrm{As}^{3+}$ concentrations. B The correlation between the logarithm of $\mathrm{As}^{3+}$ concentration and fluorescence intensity at $520 \mathrm{~nm}$ wavelength. C The fluorescence intensity of the sensor is: (a)without $\mathrm{As}^{3+}$, (b)without Exo III, (c)without Mg ${ }^{2+}$, (d) $10 \mathrm{nM} \mathrm{As}^{3+}, 2$ unit/ $\mu \mathrm{L}$ Exo III, and $100 \mathrm{mM} \mathrm{Mg}^{2+}$. D Selectivity investigation of sensing platform for $\mathrm{As}^{3+}$ against other competing heavy metal ions [112] 
properties of Au-doped carbon dots $\left(\mathrm{CD}_{\mathrm{Au}}\right)$ and high specificity of Ars-7 aptamer, which is reported by Kim. $\mathrm{CD}_{\mathrm{Au}}$ could effectively catalyze the nano-reaction of $\mathrm{AgNO}_{3}$ reduction by glucose, which produced yellow silver nanosal with a strong SPR absorption peak at $420 \mathrm{~nm}$. Ars-7 aptamer could inhibit the catalytic activity of $C D_{A u}$, leading to change of color of the solution to become lighter. After $\mathrm{As}^{3+}$ was added, it was bound to the aptamer and released free carbon dots. The catalytic activity of $C D_{A u}$ was therefore restored, resulting in linear enhancement of solution color and Abs signals. The linear relationship for SPR spectrophotometric assay was in the range of $0.025-0.75 \mu \mathrm{g} / \mathrm{L}$, with detection limit of $0.01 \mu \mathrm{g} / \mathrm{L}$ for the determination of $\mathrm{As}^{3+}$.

Similar to $\mathrm{T}-\mathrm{Hg}^{2+}-\mathrm{T}, \mathrm{Ag}^{+}$can form $\mathrm{C}-\mathrm{Ag}^{+}-\mathrm{C}$ mismatch with cytosine. Via this characteristic, the sensitive aptamer sensor can be designed for $\mathrm{Ag}^{+}$detection. For example, Li et al. [114] designed an aptamer sequence that could form a hairpin structure with $\mathrm{Ag}^{+}$, and established a colorimetric sensor based on $\mathrm{Ag}^{+}$and Exo III-dependent DNA cleavage recycling amplification (Fig. 5). In this sensor, Exo III could cut the dsDNA carrying $\mathrm{Ag}^{+}$, and the released ssDNA was adsorbed on the surface of AuNPs. The strong electrostatic repulsion among the AuNPs therefore promoted the dispersion of AuNPs in high salt media, and the color changed to green (disperse AuNPs) under dark-field microscopy observation. On this basis, the detection limit for the $\mathrm{Ag}^{+}$sensor was as low as $41 \mathrm{fM}$.

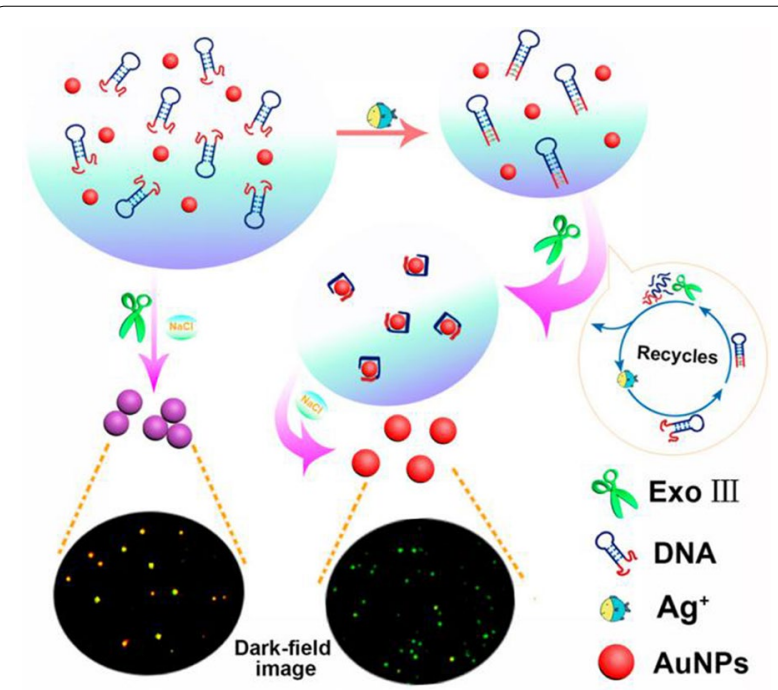

Fig. 5 The interaction between aptamer and $\mathrm{Ag}^{+}$can be detected by dark field microscope under the action of Exo III dependent DNA cleavage cycle amplification. [114]

\section{Multi-target detection}

In the actual sample detection, many heavy metal ions generally exist in different biological and environmental systems [115]. The heavy metal ions pollution produced by the industrial production process will enter the human body through water and food. Besides, the sensor for detecting a single target is easily disturbed by other heavy metal ions. Therefore, it is of great significance to develop a method that can detect many types of heavy metal ions at the same time. For example, Khoshbin et al. [116] designed a fluorescent aptasensor that could simultaneously detect $\mathrm{Hg}^{2+}$ and $\mathrm{Ag}^{+}$in about $10 \mathrm{~min}$. This sensor contained specific identification $\mathrm{Hg}^{2+}$ and $\mathrm{Ag}^{+}$ aptamers that were modified by FAM and fixed on different regions of GO. The aptamers can be eluted from GO by target and recover the fluorescence signal suppressed by GO. Via monitoring of fluorescence recovery rate to determine the ion concentration, the detection limit for $\mathrm{Hg}^{2+}$ and $\mathrm{Ag}^{+}$were as low as $1.33 \mathrm{pM}$ and $1.01 \mathrm{pM}$, respectively. Similar to the principle of above sensor, Lu et al. [117] constructed a fluorescent aptasensor based on GO and fluorescently labeled aptamer probes for simultaneous detection of $\mathrm{Pb}^{2+}, \mathrm{Hg}^{2+}$, and $\mathrm{Ag}^{+}$. In general, these free single-stranded probes were adsorded on the surface of GO. Owing to the close proximity between fluorophores and GO, the fluorescence resonance energy transfer occurred, resulting in fluorescence quenching and signals weakening. The fluorescence intensity was restored after the target ions were added. The fluorescence intensities for the three fluorophores and corresponding ions concentration had good linear dependence. Besides this prepared sensor, Lu et al. [118] also developed a fluorescent sensor that could detect $\mathrm{Pb}^{2+}$ and $\mathrm{Hg}^{2+}$ at the same time. The sensor had two kinds of quenchers which could suppress the fluorescence signal under general conditions. The ions bonded with the aptamer and destroyed its stem-loop structure after addition of the target, and thus the fluorescence signal was restored. The average recovery in the actual sample was $96.55-102.78 \%$, which proved that this method had high accuracy. Moreover, Feng and Li [119] developed an electrochemiluminescence (ECL) sensor for simultaneous detection of $\mathrm{Pb}^{2+}$ and $\mathrm{Hg}^{2+}$. The $\mathrm{Pb}^{2+}$ and $\mathrm{Hg}^{2+}$ aptamers combined with targets to form G-quadruple and hairpin structure, resulting in ECL intensity difference. The sensitivities of the sensor for detecting $\mathrm{Pb}^{2+}$ and $\mathrm{Hg}^{2+}$ were $24 \mathrm{pM}$ and $4.1 \mathrm{pM}$, respectively. Based on regulation of oxidase-mimicking activity of $\mathrm{Mn}_{3} \mathrm{O}_{4}$ nanoparticles $\left(\mathrm{Mn}_{3} \mathrm{O}_{4} \mathrm{NPs}\right)$ by oligonucleotides, Wang et al. [120] established a colorimetric method for the detection of $\mathrm{Hg}^{2+}$ and $\mathrm{Cd}^{2+}$. With combination of target and aptamer, TMB changed from light green to yellow under $\mathrm{Mn}_{3} \mathrm{O}_{4}$ NPs catalysis. 
Optical aptasensors have been widely used because of its simple preparation and intuitive results. Table 2 integrates the application of aptasensor in the detection of heavy metal ions in recent five years.

\section{Electrochemical aptasensors}

Electrochemical aptasensor consists of electrodes and recognition molecules with electrochemical activity. After the aptamer fixed on the electrode surface combines with the target, the concentration of the target is detected by collecting the changes of electrochemical signals such as voltage, current, conductivity and impedance [121]. Common electrochemical methods include sandwich method, competition method and electrochemical impedance spectroscopy method [122, 123]. In addition, electrochemical sensors can also be combined with electrochemical signal amplification strategy to achieve the purpose of amplifying the signal. Electrochemical sensors are gradually favored by researchers because of their characteristics, such as multiple analysis, fast detection speed, high sensitivity and relatively low cost $[124,125]$. Table 3 integrates the application of electrochemical aptasensor in the detection of heavy metal ions in recent 5 years.

Generally, labeled electrochemical aptasensor is via labeling some functional markers with electroactive or catalytic activity by adsorption and modification at the end of the aptamer probe. The common functional markers are methylene blue (MB) and ferrocene (FC). The combination of aptamer and target leads to increased or

Table 2 A summary of developments of optical aptasensor for heavy material ions

\begin{tabular}{|c|c|c|c|c|c|}
\hline Target & Type & LOD (nM) & LinearRange (nM) & Aptamer & Refs \\
\hline $\mathrm{Pb}^{2+}$ & FRET & 4.1 & $0-50$ & AAGGG TGGGT GGGT & {$[85]$} \\
\hline $\mathrm{Pb}^{2+}$ & SERS & 0.07 & $0.13-53.33$ & GGTTG GTGTG GTGGT TGGTG TTGG & {$[86]$} \\
\hline $\mathrm{Pb}^{2+}$ & Colorimetric & 3.04 & $4.83-1447.88$ & GGGTG GGTGG GTGGGT & [87] \\
\hline $\mathrm{Pb}^{2+}$ & Colorimetric & 100 & $500-10,000$ & GTGGG TAGGG CGGGTTGG & {$[89]$} \\
\hline $\mathrm{Pb}^{2+}$ & QCM & 4 & $5-200$ & TTTTT TACCC AGGGT GGGTG GGTGG GT & [91] \\
\hline $\mathrm{Pb}^{2+}$ & Fluorescence & 60.7 & $100-1000$ & $\begin{array}{l}\text { GACGA CGGCC AGTAG CTGAC ATCAG TGTAC GATCT AGTCG } \\
\text { TC }\end{array}$ & [52] \\
\hline $\mathrm{Hg}^{+}$ & Colorimetric & 0.049 & $0.82-62$ & TTTTT TTTTT & {$[96]$} \\
\hline $\mathrm{Hg}^{+}$ & Colorimetric & 10.5 & $50-6000$ & TTTTT TTTTт TTTTт TтTтT TTт & [97] \\
\hline $\mathrm{Hg}^{+}$ & SPR & 0.026 & $0.05-100$ & TTTTT ATTCT TTCTT CCCCC CGGTT GTTTG TTT & [99] \\
\hline $\mathrm{Hg}^{+}$ & Fluorescence & 0.2 & $2-160$ & ТTCTT TCTTC TTTC & {$[100]$} \\
\hline $\mathrm{Hg}^{+}$ & FRET & 4.92 & $500-7000$ & AATAG CTTTG CTCTC TCGTTT & [101] \\
\hline $\mathrm{Cd}^{2+}$ & Colorimetric & 9.96 & $17.79-177.92$ & $\begin{array}{l}\text { ACCGA CCGTG CTGGA CTCTG GACTG TTGTG GTATT ATTTT } \\
\text { TGGTT GTGCA GTATG AGCGA GCGTT GCG }\end{array}$ & [105] \\
\hline $\mathrm{Cd}^{2+}$ & Fluorescence & 2.15 & $7.19-5000$ & GGGGA CTGTT GTGGT ATTATTTTTG GTTGT GCAGT & {$[107]$} \\
\hline $\mathrm{Cd}^{2+}$ & Colorimetric & $5 \times 10^{-3}$ & $0.02-2 \times 10^{5}$ & $\begin{array}{l}\text { ACCGACCGTGCTGGACTCTGGACTGTTGTGGTA TTATTTTTG } \\
\text { GTTGTGCAGTATGAGCGAGCGTTGCG }\end{array}$ & [108] \\
\hline $\mathrm{As}^{3+}$ & Colorimetric & 185 & / & $\begin{array}{l}\text { GGTAA TACGA CTCAC TATAG GGAGA TACCA GCTTA TTCAA } \\
\text { TTTAA GAACA ACCAA CGTCG CTCCG GGTAC TTCTT CATCA } \\
\text { GATAG TAAGC AATCT }\end{array}$ & [110] \\
\hline $\mathrm{As}^{3+}$ & Colorimetric & 217 & $12.8-1282.9$ & $\begin{array}{l}\text { GGTAA TACGC TCACT ATAGG GAGAT ACCAG CTTAT TCAAT } \\
\text { TTTAC AGAAC AACCA ACGTC GCTCC GGGTA CTTCTTCATC } \\
\text { GAGAT AGTAA GTGCA ATCT }\end{array}$ & [111] \\
\hline $\mathrm{As}^{3+}$ & Fluorescence & $2 \times 10^{-3}$ & $0.001-1000$ & $\begin{array}{l}\text { GGTAA TACGA CTCAC TATAG GGAGA TACCA GCTTA TTCAA } \\
\text { TTTTA CAGAA CAACC AACGT CGCTC CGGGT ACTTC TTCAT } \\
\text { CGAGA TAGTA AGTGC AATCT }\end{array}$ & [112] \\
\hline $\mathrm{As}^{3+}$ & Colorimetric & 0.128 & $0.32-9.62$ & ATGCA AACCC TTAAG AAAGT GGTCG TCCAA AAAAC CATTG & [113] \\
\hline $\mathrm{Ag}^{+}$ & Colorimetric & $4.1 \times 10^{-5}$ & $5.7 \times 10^{-5}-0.57$ & $\begin{array}{l}\text { CCCCC CCGTG GGTAG GGCGG GTTGG ACCCT ACCCA CCCCC } \\
\text { CCG }\end{array}$ & [114] \\
\hline $\mathrm{Ag}^{+} ; \mathrm{Hg}^{2+}$ & Fluorescence & $1.01 \times 10^{-3} ; 1.33 \times 10^{-3}$ & $\begin{array}{l}0.05-50 ; \\
0.05-50\end{array}$ & $\begin{array}{l}\text { CCCCC CCCCC CC; } \\
\text { TTTTTTTTTTTT }\end{array}$ & [116] \\
\hline $\mathrm{Hg}^{2+} ; \mathrm{Pb}^{2+} ; \mathrm{Ag}^{+}$ & Fluorescence & $0.2 ; 0.5 ; 2$ & $0.3-14 ; 0.8-38 ; 4.2-210$ & $\begin{array}{l}\text { TTCTT TCTTA ACTTG TTTGT TCAC; } \\
\text { GGAAG GTGTG GAAGG AAC; } \\
\text { CTCTC TTCTC TTCAT AAATC AACAC AACAC ACAAA }\end{array}$ & [117] \\
\hline $\mathrm{Pb}^{2+} ; \mathrm{Hg}^{2+}$ & ECL & $0.024 ; 0.0041$ & $0.1-10^{4} ; 0.01-100$ & $\begin{array}{l}\text { AAAAA AAAAG GGG } \\
\text { TTTTT TAAAA TTTTTT }\end{array}$ & [119] \\
\hline
\end{tabular}


Table 3 A summary of developments of electrochemical aptasensor for heavy material ions

\begin{tabular}{|c|c|c|c|c|c|}
\hline Target & nanomaterial & LOD (nM) & LinearRange (nM) & Aptamer & Refs \\
\hline $\mathrm{Hg}^{2+}$ & AuNPs/CS & $5 \times 10^{-3}$ & $0.01-500$ & TCATG TTTGT TTGTT GGCCC CCCTT CTTTC TTA & [127] \\
\hline $\mathrm{Hg}^{2+}$ & AuNPs & $1 \times 10^{-4}$ & $2 \times 10^{-3}-20$ & TTCTC TCTTC GACGT TGTGT GTT & [128] \\
\hline $\mathrm{Hg}^{2+}$ & NFs-QDs & 0.02 & $0.1-150$ & $\begin{array}{l}\text { TTTTTTTTTTT ACAGC AGATC AGTCT ATCTT CTCCT GATGG GTTCCT } \\
\text { ATTTA TAGGT GAAGC TGT }\end{array}$ & [153] \\
\hline $\mathrm{Hg}^{2+}$ & AgNPs & 25 & $25-500$ & TTTCT TCTTT CTTCC CCCCT TGTTT GTTT & [130] \\
\hline $\mathrm{Pb}^{2+}$ & ERGO & $5.1 \times 10^{-7}$ & $10^{-6}-1$ & GGTGG TGGTG GTTGT GGTGG TGGTG G & [132] \\
\hline $\mathrm{Pb}^{2+}$ & Au@Py & 2.9 & $2.4-120.7$ & GGGTG GGTGG GTGGGT & [133] \\
\hline $\mathrm{Pb}^{2+}$ & AuNPs & $8.5 \times 10^{-3}$ & $0.01-1000$ & GGGTG GGTGG GTGGG TGGGT & [134] \\
\hline $\mathrm{Pb}^{2+}$ & PtNPs@PCs & 0.018 & $0.05-1000$ & GGGTG GGTGG GTGGG TAT & [135] \\
\hline $\mathrm{Cd}^{2+}$ & $\mathrm{rGO} / \mathrm{g}-\mathrm{C}_{3} \mathrm{~N}_{4}$ & 0.337 & $1-1000$ & $\mathrm{C}_{12}$-GGGGC AGTGC CTCAC AACCT & [136] \\
\hline $\mathrm{As}^{3+}$ & CNPs & 1.18 & $6.4-1283$ & $\begin{array}{l}\text { GGTAA TACGA CTCAC TATAG GGAGA TACCA GCTTA TTCAA TTTTA } \\
\text { CAGAA CAACC AACGT CGCTC CGGGT ACTTC TTCAT CGAGA TAGTA } \\
\text { AGTGC AATCT }\end{array}$ & {$[137]$} \\
\hline $\mathrm{As}^{3+}$ & Ag-Au alloy NPs & $3.8 \times 10^{-5}$ & $0.128-128$ & $\begin{array}{l}\text { GGTAA TACGA CTCAC TAAGG GAGAT ACCAG CTTAT TCAAT TTTAC } \\
\text { AGAAC ACCAA CGTCG CTCGG GTACT TCTTC ATCGA GATAG TAAGT } \\
\text { GCAAT CT }\end{array}$ & [138] \\
\hline $\mathrm{As}^{3+}$ & / & 0.26 & $1.28-2565.7$ & $\begin{array}{l}\text { TGATGTTTGTTTACGCATGTGTGAGGAGAGGCTGGGGTGATGAATCCCAAT } \\
\text { CCC }\end{array}$ & [139] \\
\hline $\mathrm{Pb}^{2+} ; \mathrm{As}^{3+}$ & Fe-MOF@mFe $\mathrm{O}_{4} @ m C$ & $\begin{array}{l}2.27 \times 10^{-3} \\
6.73 \times 10^{-3}\end{array}$ & $\begin{array}{l}0.01-10 \\
0.01-10\end{array}$ & $\begin{array}{l}\text { CAACG GTGGG TGTGG TTGG; } \\
\text { GGTAA TACGA CTCAC TATAG GGAGA TACCA GCTTA TTCAA TTTTTA } \\
\text { CAGAA CAACC AACGT CGCTC CGGGT ACTTC TTCAT CGAGA TAGTA } \\
\text { AGTGC AATCT }\end{array}$ & [141] \\
\hline $\mathrm{Pb}^{2+} ; \mathrm{Hg}^{2+}$ & / & $\begin{array}{l}0.48 \\
0.50\end{array}$ & $\begin{array}{l}0.48-4826 ; \\
0.50-4985\end{array}$ & $\begin{array}{l}\text { CAACG GTTGG TGTGG TTGG; } \\
\text { TTCTTTCTTC CCCTT CTTTC TT }\end{array}$ & [143] \\
\hline
\end{tabular}

decreased electrochemically active substances and subsequent change of electrochemical signals. The aptamer probe for the label-free electrochemical aptasensor can directly monitor the interaction between aptamer and target without the labeling of the electroactive material [126]. Electrochemical impedance spectroscopy (EIS) is the most common method for label-free electrochemical aptasensors, which is particularly sensitive in detecting the conjugation reaction on the surface of the electrode.

\section{Mercury}

$\mathrm{Hg}^{2+}$ is a widely used target for detecting heavy metal ions by electrochemical aptasensors. $\mathrm{T}-\mathrm{Hg}^{2+}-\mathrm{T}$ is the recognition principle of electrochemical sensor for $\mathrm{Hg}^{2+}$ detection. Liu et al. [127] established a mercury ion electrochemical sensor based on $\mathrm{T}-\mathrm{Hg}^{2+}-\mathrm{T}$ structure. The aptamer-functionalized AuNPs and chitosan were modified on the glassy carbon electrode (aptamer(AuNPs/CS) 2 /GCE) because AuNPs could enhance the electron transfer and improve analytical response. The aptamer recognized the $\mathrm{Hg}^{2+}$ and folded into the hairpin structure, resulting in the electrochemical signal indicator close to the surface of the sensor. Thus, an electrochemical response was produced. Based on this mechanism for the biosensor, the logarithm of $\mathrm{Hg}^{2+}$ concentration and DPV peak current had a good linear relationship in the range of 0.01-500 nM, and the detection limit for the prepared sensor was 5 pM. Si and Tang [128] developed the electrochemical sensor for determination of mercury ions based on specificity of thymine-rich $\mathrm{Hg}^{2+}$ aptamer and high catalytic activity of template deoxynucleotidyl transferase $(\mathrm{Td} T)$. Template-independent $\mathrm{TdT}$ improved the sensitivity of sensor by lengthening the aptamer end of 3 '-OH by repeating bases, and $\mathrm{Hg}^{2+}$ aptamer brought selective interaction of thymine mismatched pairs, enhancing the specificity. Based on this strategy, the detection limit for the sensor was $0.1 \mathrm{pM}$. Moreover, a combination based on electro spun nanofibers polyethersulfone and quantum dots (NFs-QDs) was designed in another study for sensitive detection of $\mathrm{Hg}^{2+}$ [129]. In this sensor, the electrochemical signal of MB was amplified by NFs-QDs nanocomposites after the aptamer was bound to $\mathrm{Hg}^{2+}$. In another research on impedance electrochemical sensors, ink-jet printed and aptamer functionalized gold electrodes were proposed for the first time as a reliable, stable and fully scalable method for the detection of $\mathrm{Hg}^{2+}$ in water and organic solvents [130,131]. The results demonstrated that the aptasensor had good stability and remarkable repeatability under harsh conditions. The sensor could detect the $\mathrm{Hg}^{2+}$ of 0.005 ppm in organic solvents. 


\section{Lead}

In recent years, electrochemical aptasensors for $\mathrm{Pb}^{2+}$ detection are mainly based on the capture of $\mathrm{Pb}^{2+}$ by G-quadruplex. Under the same principle of recognition target, DNA sequence can realize the specific recognition of $\mathrm{Pb}^{2+}$. However, the key to developing a highly sensitive sensor is to fix the nanomaterials on the aptamer. For example, Yu et al. [132] established an ultra-sensitive electrochemical sensor for the detection of $\mathrm{Pb}^{2+}$ based on G-quadruplex aptamer and electrochemical reduction of graphene oxide (ERGO) electrode. Methylene blue (MB)-labeled G-rich aptamers were immobilized on the ERGO-modified glassy carbon electrode (GCE) by $\pi-\pi$ interaction. When $\mathrm{Pb}^{2+}$ was added, the aptamer specifically recognized $\mathrm{Pb}^{2+}$ induced allosteric G-quadruplexes and detached from the ERGO surface, and then the redox current labeled with $\mathrm{MB}$ changed significantly. The sensor detection limit for $\mathrm{Pb}^{2+}$ was $0.51 \mathrm{fM}$. Based on the $\mathrm{Pb}^{2+}$ aptamer, $\mathrm{Au}$ nanoparticles composites and polypyrrole (Au@Py), Ding et al. [133] established an electrochemical sensor for detection of $\mathrm{Pb}^{2+}$.The AuNPs of Au@Py composites could increase signal transduction and amplify the current signal when Au@Py modified on the surface of screen-printed electrode. Toluidine blue (TB) for biosensor is a redox indicator that can interact with dsDNA consisting of $\mathrm{Pb}^{2+}$ aptamer and complementary strand of the aptamer. After adding the target $\mathrm{Pb}^{2+}$, the peak current of the interaction between TB and dsDNA was lower than that without target for the combination of the aptamer and $\mathrm{Pb}^{2+}$.

Tang and colleagues [134] designed an electrochemical sensor based on label-free G-quadruplex for the detection $\mathrm{Pb}^{2+}$. Polyion oligonucleotide-labeled gold nanoparticles modified on the gold electrode, as signal-amplified probes, provided high-density negative charge on the electrode surface. The $\mathrm{Pb}^{2+}$-induced G-quadruplex formation reduced the negative charge on the surface of the electrode in the presence of $\mathrm{Pb}^{2+}$, realizing the highly selective detection of $\mathrm{Pb}^{2+}$. The sensitive aptasensor exhibited wide detection range from $10^{-11}$ to $10^{-6} \mathrm{M}$ and the detection limit of $8.5 \mathrm{pM}$. In another report on detection of $\mathrm{Pb}^{2+}$ by label-free electrochemical sensor, Jin et al. [135] adopted $\mathrm{Pb}^{2+}$ aptamer-based catalytic hairpin assembly technology and composite of platinum nanoparticles (PtNPs)/ porous carbon(PCs) (PtNPs@PCs) catalyzed hydroquinone- $\mathrm{H}_{2} \mathrm{O}_{2}$ system as signal amplification strategy. Their results showed that the electrochemical signal depended on the concentration of $\mathrm{Pb}^{2+}$ in the range of 50-1000 nM.

\section{Cadmium}

There are a few reports on electrochemical aptamer sensors to detect $\mathrm{Cd}^{2+}$ in recent years. After the IssAP08-Cd ${ }^{2+}$ aptamer was selected, it was used to prepare a label-free electrochemical aptasensor to recognize $\mathrm{Cd}^{2+}$ [68]. The aptamer was modified on the gold screen printed electrode. The conformational change of aptamer led to the change of surface impedance in the presence of $\mathrm{Cd}^{2+}$, and current density signal. Based on the reduced graphene oxide $(\mathrm{rGO}) /$ graphite carbon nitride $\left(\mathrm{g}-\mathrm{C}_{3} \mathrm{~N}_{4}\right)$ composite system $(\mathrm{GCN})$, Wang et al. [136] constructed an aptasensor with a detection limit of $0.337 \mathrm{nM}$ for $\mathrm{Cd}^{2+}$ (Fig. 6). The rGO could improve the electrical conductivity, and concentration of $\mathrm{Cd}^{2+}$ in the solution was monitored by differential anodic stripping voltammetry (DPASV).

\section{Other electrochemical sensors}

After the $\mathrm{As}^{3+}$ aptamer was reported, there were many reports on electrochemical aptasensor for the detection of $\mathrm{As}^{3+}$. For example, Mushiana et al. [137] reported an electrochemical aptasensor based on aptamer Ars-3 and carbon and gold nano-platform (CNPs/AuNPs). A thiol modified Ars-3 aptamer was immobilized on GCE modified by CNPs/AuNPs via $\mathrm{Au}-\mathrm{S}$ bond. As a signal amplifier, CNPs could effectively amplify the electrochemical signal of Ars-3 combined with $\mathrm{As}^{3+}$ on the surface of AuNPs. The detection limit for the prepared sensor was $0.092 \mathrm{ppb}$. Yadav and his colleagues [138] reported an electrochemical aptasensor based on aptamers and Ag$\mathrm{Au}$ alloy nanomaterials (Ag-Au alloy NPs) to detect $\mathrm{As}^{3+}$. The sensor was used $\mathrm{As}^{3+}$ aptamer deep trapped Ag-Au alloy NPs which modified glassy carbon electrode. The captured $\mathrm{As}^{3+}$ started the electrochemical reaction, which generated a significant increase in the current of voltammetry curves. The detection limit for the $\mathrm{As}^{3+}$ sensor was 3 pg/L. Moreover, Gu et al. [139] established an electrochemical sensor for the detection of $\mathrm{As}^{3+}$ based on intercoordination between hybridization chain reaction $(\mathrm{HCR})$ and $\mathrm{Rec}_{\mathrm{f}}$ exonuclease $\left(\mathrm{RECJ}_{\mathrm{f}}\right.$ exo) catalyzed reaction. The aptamer and ssDNA were assembled on the surface of the gold electrode, resulting in a huge charge transfer resistance $\left(R_{c t}\right)$. The aptamer sequence was specifically bound to $\mathrm{As}^{3+}$ in the presence of $\mathrm{As}^{3+}$ and DNA was dissociated. The release of HCR products could reduce $R_{c t}$, which $R E C J_{f}$ exo could further amplify this signal. The detection limit for this sensor was as low as $0.02 \mathrm{ppb}$.

According to the study on binding mechanism for $\mathrm{Au}$ and DNA, it was found that, polyA DNA could be tightly adsorbed on the surface of $\mathrm{Au}$, while the adsorption of polyT DNA was weak. Wu et al. [140] reported an 


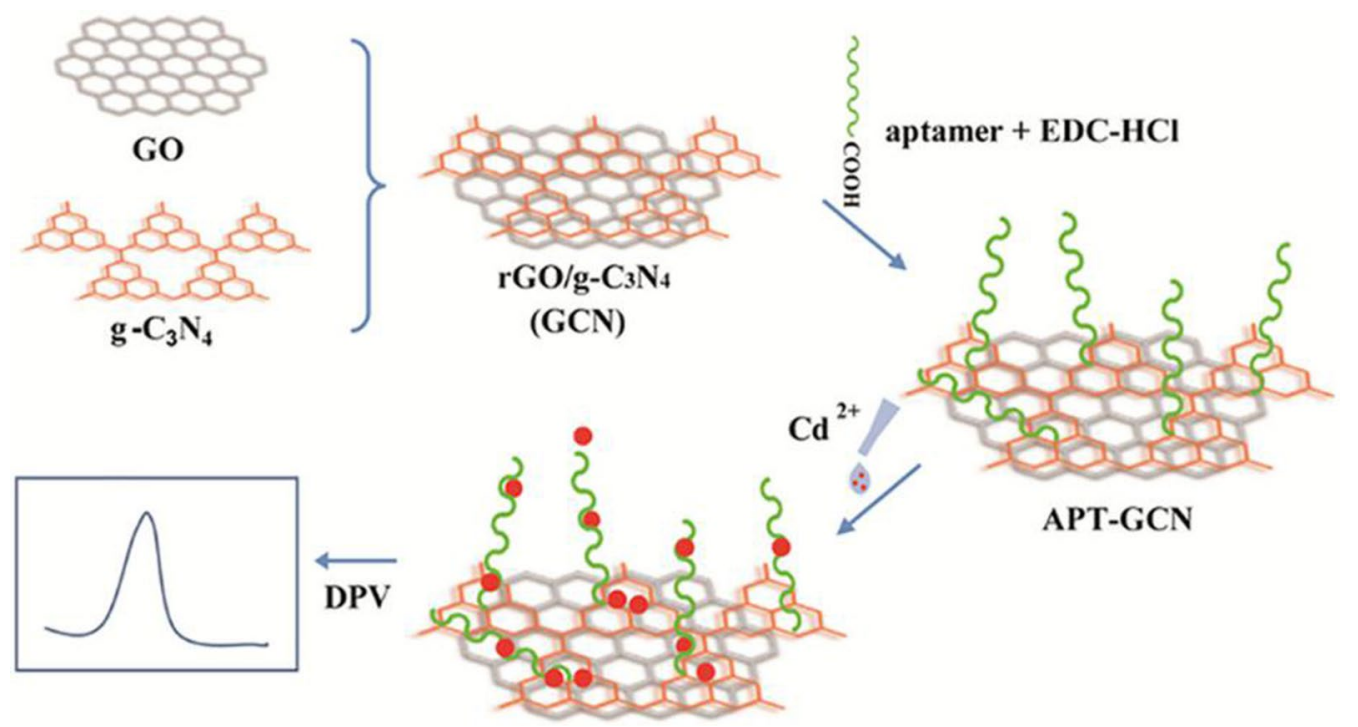

Fig. 6 Schematic illustration of the fabrication of GCN aptasensor. The sensor can produce obvious DPASV signal change when detecting Cd ${ }^{2+}$ [136]

electrochemical ion (E-ion) sensor to detect $\mathrm{Au}^{3+}$. Based on the interaction between $\mathrm{Au}^{3+}$ and adenine, $\mathrm{MB}$ as a signal switch, was modified at the end of an adenine-rich ssDNA. The complex formed between $\mathrm{Au}^{3+}$ and ssDNA hardened the probe, and $\mathrm{MB}$ was limited to enter the electrode and reduced the signal intensity (Fig. 7).

\section{Multi-target detection}

The detection of multi-target also uses the recognition effect of aptamer to the target, and the aptamers from many types of ions are fixed on the electrode. For example, Zhang et al. [141] designed new type of coreshell nanostructured composites, which could provide a large number of aptamer binding sites. The composites consisted of Fe (III)-based metal-organic framework (Fe-MOF) and mesoporous $\mathrm{Fe}_{3} \mathrm{O}_{4} @ \mathrm{C}$ nanocapsules. Via conformational transition interaction between aptamer and target, the target ions would block and obstruct the surface of the nanocomposite, causing decreased electron transfer, and further leading to the increased $R_{c t}$. The detection limits for the $\mathrm{Pb}^{2+}$ and $\mathrm{As}^{3+}$ sensor were 2.27 and $6.73 \mathrm{pM}$, respectively.

Based on aptamer recognition and resistive pulse (RP) sensor technology, Mayne et al. [142] prepared an aptamer sensor for monitoring of $\mathrm{Pb}^{2+}$ and $\mathrm{Hg}^{2+}$. $\mathrm{RP}$ had single particle resolution, which allowed the sample to be characterized. When the nanomaterials that were modified with aptamers passed through the RP sensor, the information such as charge state and density could be observed. The combination of targets led to decreased charge density, then obtaining the target concentration information. The sensor carried different aptamers to adapt to detect different targets. Figure 8 shows the binding principle of multi-target aptamers.

In another report on the detection of $\mathrm{Pb}^{2+}$ and $\mathrm{Hg}^{2+}$, a sensor with a detection limit of $0.1 \mathrm{ppb}$ was constructed [143]. In this sensor, the FC modified by aptamer was

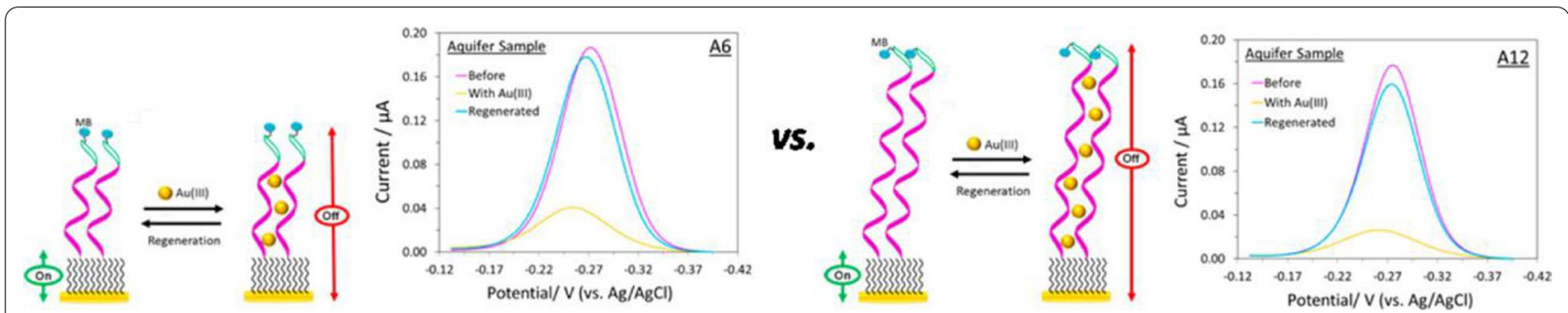

Fig. 7 The signal mechanism of six adenines (A6) or twelve adenines (A12) were used as DNA probes to construct the signal mechanism of the sensor. The combination of the target and the probe can harden the probe and reduce the MB current [140] 


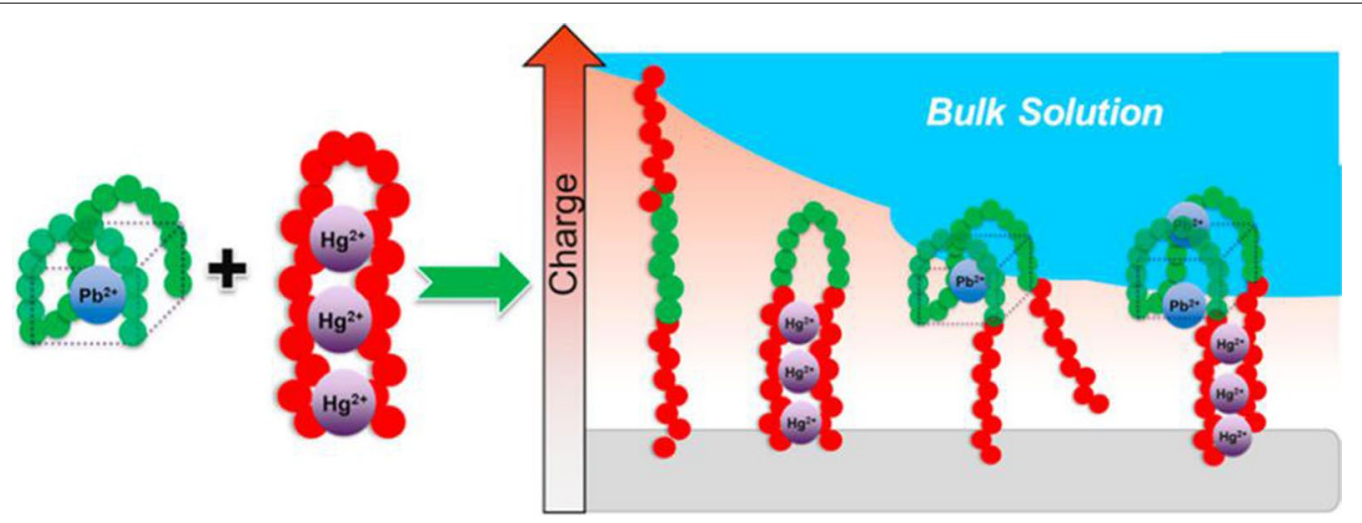

Fig. 8 Schematic diagram of double ligand binding target in multi-target aptamer sensor [142]

fixed on the screen-printed gold electrode to detect the target concentration by monitoring the electron transfer between the redox label and the electrodes.

\section{Other aptasensors}

In recent years, the aptamer sensors for detecting heavy metal ions have made great progress in their research [144-146]. The challenges of aptasensors, including specificity, sensitivity and rapid response are constantly innovating. In addition, some novel aptasensors have been reported in recent years. For example, some Field-Effect Transitor (FET)-based aptasensor was introduced. Wang et al. $[147,148]$ constructed an FET sensor based on aptamer and single-walled carbon nanotubes (SWNTs) to detect $\mathrm{Pb}^{2+}$. The double-stranded DNA containing aptamers was coupled to SWNTs. The combination of $\mathrm{Pb}^{2+}$ and aptamer led to deionization, which affected the electrical conductivity of SWNTs as an analytical signal. The sensor detected $\mathrm{Pb}^{2+}$ concentration as low as $0.39 \mathrm{ng} / \mathrm{L}$. Due to its anisotropic properties and molecular sensitivity, liquid crystals (LCs) have been used for detecting chemical and biological events by converting chemical and biological intereactions into optical signals under a polarized light microscope. Nguyen et al. [149] reported a sensor based on $\mathrm{As}^{3+}$ aptamer Ars-3 and label-free LCs. Cetyltrimethylammonium bromide (CTAB) installed independently at the aqueous/LC interface could induce homeotropic orientation of LCs. The negatively charged aptamers interfered with self-assembly of positively charged CTAB on the aqueous/LC interface. The orientational of LCs was changed into planar state without $\mathrm{As}^{3+}$. The addition of $\mathrm{As}^{3+}$ could weaken the interference of aptamer to CTAB and make LC keep in a homeotropic state. The detection limit for this sensor was $50 \mathrm{nM}$.

In addition, Ertan et al. [150] established an ellipsometric aptasensor to detect $\mathrm{Hg}^{2+}$. Chen et al. [151] established a luminescence resonance energy transfer (LRET) sensor for detecting $\mathrm{As}^{3+}$. Liu et al. [152] established a sensor that can detect $\mathrm{Hg}^{2+}$ based on the attenuated total reflection surface enhanced infrared absorption spectroscopy (ATR-SEIRAS).

\section{Conclusion and future prospect}

In the past three decades, aptamers have been widely used in disease diagnosis, targeted drug delivery, environmental detection, pesticide residues and other fields, because of their excellent properties, such as easy modification, low cost and strong specificity. In order to detect heavy metal ions by aptasensor, two problems should be solved. First, heavy metal ions have the characteristics of simple conformation and single binding site, so it is difficult to obtain aptamers with high specificity and high affinity. Secondly, due to the small molecular weight of the target, it is necessary to overcome the huge steric hindrance when combining with the aptamer, which poses a great challenge to the sensitivity of the sensor. The aptamers of heavy metal ions mainly include $\mathrm{Pb}^{2+}$, $\mathrm{Hg}^{2+}, \mathrm{Cd}^{2+}$ and $\mathrm{As}^{3+}$, which are heavily polluted from industry. Aptasensors have therefore become an important tool to detect heavy metal pollution. Some sensors detect the concentration of heavy metal ions to as low as fM concentration.

Although aptasensors have made great achievements in the detection of heavy metal ions in the past few decades, there are still many challenges. First, the reports on the selection of aptamers for heavy metal ions are mainly focused on the common ions for industrial pollution, while the aptamers from other heavy metal ions are rarely reported. Even many heavy metal ions have not obtained aptamers with high affinity and strong specificity. Secondly, the sensor with higher sensitivity has higher requirements for sample pretreatment, laboratory equipment and professional operators, so it 
is difficult to achieve on-site detection. Third, the construction of the sensor is difficult, and the stability and toxicity of nano-materials will limit the application of the aptasensor.

In order to solve these problems, further research on aptasensors to detect heavy metal ions should pay attention to the diversity of targets and commercialization of sensors. In order to deal with detection of various targets, the future development of the sensor should detect several heavy metal ions in one platform. The aptamer with high affinity and detection methods with high sensitivity can be designed as a sensitive aptasensor for heavy metal ions detection. At present, aptasensors mostly rely on laboratory instruments and professional operators during the detection of actual samples, it is therefore easy to be affected by other ions or organic compounds, which often requires complex pretreatment steps. All these measures will enable the aptamer sensor to achieve rapid and sensitive on-site detection. In summary, we expect the aptasensors to become an effective analytical tool for the detection of heavy metal ions to meet various challenges.

\begin{abstract}
Abbreviations
SELEX: Systematic evolution of ligands by exponential enrichment; NPs: Nanoparticles; CD: Circular dichroism; GO: Graphene oxide; ITC: Isothermal titration calorimetry; SS-PD: Structure-switching particle display; MD: Molecular dynamics; SPR: Surface plasmon resonance; SERS: Surface enhanced Raman scattering; FRET: Fluorescence resonance energy transfer; $\mathrm{CL}$ : Chemiluminescence; ECL: Electrochemiluminescence; TBA: Thrombin binding aptamer; UCNPs: Upconversion nanoparticles; AuNPs: Gold nanoparticles; GNP: Gold nanoparticles; QCM: Quartz crystal microbalance; T-ssDNA: Thymine-rich ssDNA; AMB: Aptamers-functionalized magnetic beads; STP: Signal transduction probe; DPI: Dual polarization interferometry; 6-FAM: 6-Carboxyfluorescein; CTAB: Cetyltrimethyl ammonium bromide; $\mathrm{CD}_{\mathrm{Au}}$ : Au-doped carbon dots; $\mathrm{MB}$ : Methylene blue; FC: Ferrocene; EIS: Electrochemical impedance spectroscopy; TdT:Template deoxynucleotidyl transferase; NFs-QDs: Nanofibers polyethersulfone and quantum dots; ERGO: Electrochemical reduction of graphene oxide; GCE: Glassy carbon electrode; TB: Toluidine blue; DPASV: Differential anodic stripping voltammetry; HCR: Hybridization chain reaction; Fe-MOF: Fe (III)-based metal-organic framework; SWNTs: Single-walled carbon nanotubes; CTAB: Cetyltrimethylammonium bromide.
\end{abstract}

\section{Acknowledgements}

Wenfei Guo, Chuanxiang Zhang, Tingting Ma, Xueying Liu, Zhu Chen, Song $\mathrm{Li}$, Yan Deng are grateful to Hunan University of technology, China for support. Song Li and Yan Deng are grateful for the financial support provided by National Nature Science Foundation of China (NSFC). Yan Deng are grateful for the National Key Research and Development Program of China.

\section{Authors' contributions}

WFG wrote the manuscript, CXZ and TTM checked different sections of the manuscript. XYL, ZC, SL and YD edited the manuscript. All authors read and approved the final manuscript.

\section{Funding}

This work was supported by the National Key Research and Development Program of China (2018YFC1602905), the NSF of China (61871180, 61971187, and 61901168).

\section{Availability of data and materials}

Not applicable.

\section{Declarations}

Ethics approval and consent to participate Not applicable.

\section{Consent for publication}

We have included eight figures (Figs. 1-8) from previously published literature with required copyright permission from the copyright holder. We have mentioned this in the manuscript with proper citation.

\section{Competing interests}

The authors declare that they have no competing interests.

Received: 24 March 2021 Accepted: 26 May 2021

Published online: 01 June 2021

\section{References}

1. Geng H, Xu Y, Zheng L, Gong H, Dai L, Dai X. An overview of removing heavy metals from sewage sludge: achievements and perspectives. Environ Pollut. 2020;266:115375.

2. Yuan J, Lu Y, Wang C, Cao X, Chen C, Cui H, et al. Ecology of industrial pollution in China. Ecosyst Health Sustain. 2020;6:1779010.

3. Zhang Y, Wang B, Cheng Q, Li X, Li Z. Removal of toxic heavy metal ions ( $\mathrm{Pb}, \mathrm{Cr}, \mathrm{Cu}, \mathrm{Ni}, \mathrm{Zn} \mathrm{Co}, \mathrm{Hg}$, and $\mathrm{Cd}$ ) from waste batteries or lithium cells using nanosized metal oxides: a review. J Nanosci Nanotechnol. 2020;20:7231-54.

4. Zhang Y, Wu D, Wang C, Fu X, Wu G. Impact of coal power generation on the characteristics and risk of heavy metal pollution in nearby soil. Ecosyst Health Sustain. 2020;6:1787092.

5. Chen S-Y, Li Z, Li K, Yu X-Q. Small molecular fluorescent probes for the detection of lead, cadmium and mercury ions. Coord Chem Rev. 2021:429:213691.

6. Farzin L, Shamsipur M, Sheibani S. A review: aptamer-based analytical strategies using the nanomaterials for environmental and human monitoring of toxic heavy metals. Talanta. 2017;174(619):627.

7. Wang L, Peng X, Fu H, Huang C, Li Y, Liu Z. Recent advances in the development of electrochemical aptasensors for detection of heavy metals in food. Biosens Bioelectron. 2020;147:111777.

8. Buledi JA, Amin S, Haider SI, Bhanger MI, Solangi AR. A review on detection of heavy metals from aqueous media using nanomaterialbased sensors. Environ Sci Pollut Res. 2020. https://doi.org/10.1007/ s11356-020-07865-7.

9. Hao Y, Wu X, Guo Y. Study on test and detection method of mechanical properties of heavy metal contaminated soil. Soil and Sedi Contam. 2020;29:929-39.

10. Zhang L, Peng D, Liang RP, Qiu JD. Graphene-based optical nanosensors for detection of heavy metal ions. TrAC, Trends Anal Chem. 2018;102:280-9.

11. Liu X, Yu K, Zhang H, Zhang X, Zhang H, Zhang J, et al. A portable electromagnetic heating-microplasma atomic emission spectrometry for direct determination of heavy metals in soil. Talanta. 2020;219:121348.

12. Pyo J, Hong S, Kwon Y, Kim MS, Cho KH. Estimation of heavy metals using deep neural network with visible and infrared spectroscopy of soil. Sci Total Environ. 2020;741:140162.

13. Ullah N, Mansha M, Khan I, Qurashi A. Nanomaterial-based optical chemical sensors for the detection of heavy metals in water: recent advances and challenges. TrAC, Trends Anal Chem. 2018;100:155-66.

14. Duan C, Fang L, Yang C, Chen W, Cui Y, Li S. Reveal the response of enzyme activities to heavy metals through in situ zymography. Ecotoxicol Environ Saf. 2018;156:106-15.

15. Li C, Ma J, Shi H, Hu X, Xiang Y, Li Y, et al. Design of a stretchable DNAzyme for sensitive and multiplexed detection of antibodies. Anal Chim Acta. 2018;1041:102-7.

16. Selvaraj U, Venu-Babu P, Thilagaraj WR. Application of H412R mutant alkaline phosphatase for removal of heavy metals from single-ion solutions and effluents. Int J Environ Sci Technol. 2018;16:1329-36.

17. Ali MH, Elsherbiny ME, Emara M. Updates on aptamer research. Int J Mol Sci. 2019;20:2511 
18. Wang T, Chen C, Larcher L, Barrero RA, Veedu RN. Three decades of nucleic acid aptamer technologies: lessons learned, progress and opportunities on aptamer development. Biotechnol Adv. 2019;37:28-50.

19. Poolsup S, Kim C-Y. Therapeutic applications of synthetic nucleic acid aptamers. Curr Opin Biotechnol. 2017;48:180-6.

20. Zhang Y, Lai BS, Juhas M. Recent advances in aptamer discovery and applications. Molecules. 2019;24:941.

21. Xiong Y, Zhang J, Yang Z, Mou Q, Ma Y, Xiong Y, et al. Functional DNA regulated CRISPR-Cas12a sensors for point-of-care diagnostics of nonnucleic-Acid targets. J Am Chem Soc. 2020;142:207-13.

22. Babu E, Bhuvaneswari J, Mareeswaran PM, Thanasekaran P, Lee H-M Rajagopal S. Transition metal complexes based aptamers as optical diagnostic tools for disease proteins and biomolecules. Coord Chem Rev. 2019;380:519-49.

23. Ding J, Qin W. Recent advances in potentiometric biosensors. TrAC Trends Anal Chem. 2020;124:115803.

24. Liu M, Khan A, Wang Z, Liu Y, Yang G, Deng Y, et al. Aptasensors for pesticide detection. Biosens Bioelectron. 2019;130:174-84.

25. Alkhamis O, Canoura J, Yu H, Liu Y, Xiao Y. Innovative engineering and sensing strategies for aptamer-based small-molecule detection. TrAC Trends Anal Chem. 2019;121:115699.

26. Liu B, Liu J. Sensors and biosensors based on metal oxide nanomaterials. TrAC Trends Anal Chem. 2019;121:115690

27. Mao K, Zhang H, Wang Z, Cao H, Zhang K, Li X, et al. Nanomaterialbased aptamer sensors for arsenic detection. Biosens Bioelectron. 2020;148:111785.

28. Chen X, Zhao Y, Zhao X, Wu J, Zhu L, Zhang X, et al. Selective pressures of heavy metals on microbial community determine microbial functional roles during composting: sensitive, resistant and actor. J Hazard Mater. 2020:398:122858.

29. Liu Y, Deng Y, Dong H, Liu K, He N. Progress on sensors based on nanomaterials for rapid detection of heavy metal ions. Sci China Chem. 2016;60:329-37.

30. Lan L, Yao Y, Ping J, Ying Y. Recent progress in nanomaterial-based optical aptamer assay for the detection of food chemical contaminants. ACS Appl Mater Interfaces. 2017;9:23287-301.

31. Li L, Xing H, Zhang J, Lu Y. Functional DNA molecules enable selective and stimuli-responsive nanoparticles for biomedical applications. Acc Chem Res. 2019;52:2415-26.

32. Ranjan S, Dasgupta N, Lichtfouse E. Nanopackaging in food and electronics. Berlin: Springer International Publishing; 2017.

33. Sahai N, Gogoi M, Ahmad N. Mathematical modeling and simulations for developing nanoparticle-based cancer drug delivery systems: a review. Curr Pathobiol Rep. 2021;9:1-8.

34. Yan J, Xiong H, Cai S, Wen N, He Q, Liu Y, et al. Advances in aptamer screening technologies. Talanta. 2019;200:124-44.

35. Liu Q, Wang H, Han P, Feng X. Fluorescent aptasensing of chlorpyrifos based on the assembly of cationic conjugated polymer-aggregated gold nanoparticles and luminescent metal-organic frameworks. Analyst. 2019;144:6025-32.

36. Komarova N, Andrianova M, Glukhov S, Kuznetsov A. Selection, characterization, and application of ssDNA aptamer against furaneol. Molecules. 2018;23:3159.

37. Ho LSJ, Fogel R, Limson JL. Generation and screening of histamine-specific aptamers for application in a novel impedimetric aptamer-based sensor. Talanta. 2020;208:120474.

38. Luo Z, He L, Wang J, Fang X, Zhang L. Developing a combined strategy for monitoring the progress of aptamer selection. Analyst. 2017:142:3136-9.

39. Boussebayle A, Groher F, Suess B. RNA-based capture-SELEX for the selection of small molecule-binding aptamers. Methods. 2019:161:10-5.

40. Zhou W, Saran R, Liu J. Metal sensing by DNA. Chem Rev. 2017:117:8272-325.

41. Chatterjee B, Kalyani N, Anand A, Khan E, Das S, Bansal V, et al. GOLD SELEX: a novel SELEX approach for the development of high-affinity aptamers against small molecules without residual activity. Microchim Acta. 2020;187:618.

42. Munzar JD, Ng A, Juncker D. Duplexed aptamers: history, design, theory, and application to biosensing. Chem Soc Rev. 2019;48:1390-419.
43. Saito S. SELEX-based DNA aptamer selection: a perspective from the advancement of separation techniques. Anal Sci. 2021;37:17-26.

44. Yan S-R, Foroughi MM, Safaei M, Jahani S, Ebrahimpour N, Borhani F, et al. A review: recent advances in ultrasensitive and highly specific recognition aptasensors with various detection strategies. Int J Biol Macromol. 2020;155:184-207.

45. Green R, Ellington AD, Szostak JW. In vitro genetic analysis of the Tetrahymena self-splicing intron. Nature. 1990;347:406-8.

46. Wang J, Wang Q, Luo Y, Gao T, Zhao Y, Pei R. In vitro selection of ssDNA aptamers that can specifically recognize and differentiate riboflavin and its derivative FAD. Talanta. 2019:204:424-30.

47. Chinnappan R, Eissa S, Alotaibi A, Siddiqua A, Alsager OA, Zourob M. In vitro selection of DNA aptamers and their integration in a competitive voltammetric biosensor for azlocillin determination in waste water. Anal Chim Acta. 2020;1101:149-56.

48. Wu X, Diao D, Lu Z, Han Y, Xu S, Lou X. Phthalic acid ester-binding DNA aptamer selection, characterization, and application to an electrochemical aptasensor. J Vis Exp. 2018;133:e56814.

49. Chen Y, Ding X, Zhu D, Lin X, Xie Z. Preparation and evaluation of highly hydrophilic aptamer-based hybrid affinity monolith for on-column specific discrimination of ochratoxin A. Talanta. 2019;200:193-202.

50. Rajendran $M$, Ellington $A D$. Selection of fluorescent aptamer beacons that light up in the presence of zinc. Anal Bioanal Chem. 2008;390:1067-75.

51. Wang H, Cheng H, Wang J, Xu L, Chen H, Pei R. Selection and characterization of DNA aptamers for the development of light-up biosensor to detect Cd(II). Talanta. 2016:154:498-503.

52. Chen Y, Li H, Gao T, Zhang T, Xu L, Wang B, et al. Selection of DNA aptamers for the development of light-up biosensor to detect $\mathrm{Pb}(\mathrm{II})$. Sens Actuators, B Chem. 2018;254:214-21.

53. Wu Y, Zhan S, Wang L, Zhou P. Selection of a DNA aptamer for cadmium detection based on cationic polymer mediated aggregation of gold nanoparticles. Analyst. 2014;139:1550-61.

54. Kim M, Um HJ, Bang S, Lee S-H, Oh S-J, Han J-H, et al. Arsenic removal from vietnamese groundwater using the arsenic-binding DNA aptamer Environ Sci Technol. 2009;43:9335-40.

55. Wrzesinski J, Ciesiolka J. Characterization of structure and metal ions specificity of $\mathrm{CO}^{2+}$-binding RNA aptamers. Biochemistry. 2005; 44:6257-68.

56. Xing L, Zhang Y, Yang J. Graphene oxide-assisted non-immobilized SELEX of chiral drug ephedrine aptamers and the analytical binding mechanism. Biochem Biophys Res Commun. 2019:514:134-9.

57. Zhao X, Dai X, Zhao S, Cui X, Gong T, Song Z, et al. Aptamer-based fluorescent sensors for the detection of cancer biomarkers. Spectrochim Acta Part A Mol Biomol Spectrosc. 2021;247:119038.

58. Cho YS, Lee EJ, Lee G-H, Hah SS. Aptamer selection for fishing of palladium ion using graphene oxide-adsorbed nanoparticles. Bioorg Med Chem Lett. 2015;25:5536-9.

59. Liu C, LiY, Xiong C, Nie Z. Development of capillary-paper spray for small-molecule analysis in complex samples. Anal Bioanal Chem. 2021:413:1099-106.

60. Zeng Y, Liang D, Zheng P, Zhang Y, Wang Z, Mari GM, et al. A simple and rapid immunochromatography test based on readily available filter paper modified with chitosan to screen for 13 sulfonamides in milk. J Dairy Sci. 2021;104:126-33.

61. Prabu SS, Ch'ng ES, Woon PY, Chen J-H, Tang T-H, Citartan M. Unravelling the diagnostic and therapeutic potentialities of a novel RNA aptamer isolated against human pituitary tumour transforming gene 1 (PTTG1) protein. Anal Chim Acta. 2020;1138:181-90.

62. Tuerk C, Gold L. Systematic evolution of ligands by exponential enrichment: RNA ligands to bacteriophage T4 DNA polymerase. Science. 1990:249:505-10.

63. Kawakami J, Imanaka H, Yokota Y, Sugimoto N. In vitro selection of aptamers that act with $\mathrm{Zn}^{2+}$. J Inorg Biochem. 2000:82:197-206.

64. Ranjbar B, Gill P. Circular dichroism techniques: biomolecular and nanostructural analyses-a review. Chem Biol Drug Des. 2009:74:101-20.

65. Kim R, Youn Y-S, Kang M, Kim E. Platform-and label-free detection of lead ions in environmental and laboratory samples using G-quadraplex probes by circular dichroism spectroscopy. Sci Rep. 2020;10:20461.

66. He Y, Zhou L, Deng L, Feng Z, Cao Z, Yin Y. An electrochemical impedimetric sensing platform based on a peptide aptamer identified by 
high-throughput molecular docking for sensitive L-arginine detection. Bioelectrochemistry. 2021;137:107634.

67. Liu X, Hou Y, Chen S, Liu J. Controlling dopamine binding by the new aptamer for a FRET-based biosensor. Biosens Bioelectron. 2020;173:112798

68. Li Y, Ran G, Lu G, Ni X, Liu D, Sun J, et al. Highly sensitive label-free electrochemical aptasensor based on screen-printed electrode for detection of cadmium (II) ions. J Electrochem Soc. 2019;166:B449-55.

69. Ran G, Wu F, Ni X, Li X, Li X, Liu D, et al. A novel label-free electrochemical aptasensor with one-step assembly process for rapid detection of lead (II) ions. Sens Actuators B Chem. 2020;320:128326.

70. Gordon CKL, Eisenstein M, Soh HT. Direct selection strategy for isolating aptamers with $\mathrm{pH}$-sensitive binding activity. ACS Sens. 2018;3:2574-80.

71. Qu H, Csordas AT, Wang J, Oh SS, Eisenstein MS, Soh HT. Rapid and label-free strategy to isolate aptamers for metal ions. ACS Nano. 2016;10:7558-65.

72. Mohaddeseh HM, Jaber JS. A molecular dynamics study proposing the existence of structural interaction between cancer cell receptor and RNA aptamer. J Inorg Organomet Polym Mater. 2020;30:4520-32.

73. Khoshbin Z, Housaindokht MR, Izadyar M, Bozorgmehr MR, Verdian A. Theoretical design and experimental study of new aptamers with the improved target-affinity: new insights into the $\mathrm{Pb}^{2+}$-specific aptamers as a case study. J Mol Liq. 2019;289:111159.

74. Chen Y, Zhu Q, Zhou X, Wang R, Yang Z. Reusable, facile, and rapid aptasensor capable of online determination of trace mercury. Environ Int. 2021;146:106181.

75. Zhang N, Liu B, Cui X, Li Y, Tang J, Wang H, et al. Recent advances in aptasensors for mycotoxin detection: On the surface and in the colloid. Talanta. 2021;223:121729.

76. Kaur H, Shorie M. Nanomaterial based aptasensors for clinical and environmental diagnostic applications. Nanoscale Advances. 2019;1:2123-38.

77. Acha ND, Elosúa C, Corres JM, Arregui FJ. Fluorescent sensors for the detection of heavy metal ions in aqueous media. Sensors. 2019;19:599.

78. Aloisi A, Torre AD, Benedetto AD, Rinaldi R. Bio-recognition in spectroscopy-based biosensors for *heavy metals-water and waterborne contamination analysis. Biosensors. 2019;9:96.

79. Berlina AN, Zherdev AV, Dzantiev BB. Progress in rapid optical assays for heavy metal ions based on the use of nanoparticles and receptor molecules. Mikrochim Acta. 2019;186:172.

80. Devi P, Thakur A, Lai RY, Saini S, Jain R, Kumar P. Progress in the materials for optical detection of arsenic in water. TrAC, Trends Anal Chem. 2019;110:97-115.

81. Zhou Y, Mahapatra C, Chen H, Peng X, Ramakrishna S, Nanda HS. Recent developments in fluorescent aptasensors for detection of antibiotics. Curr Opin Biomed Eng. 2020;13:16-24.

82. Taghdisi SM, Danesh NM, Lavaee P, Ramezani M, Abnous K. An aptasensor for selective, sensitive and fast detection of lead(II) based on polyethyleneimine and gold nanoparticles. Environ Toxicol Pharmacol. 2015;39:1206-11.

83. Yang D, Liu X, Zhou Y, Luo L, Zhang J, Huang A, et al. Aptamer-based biosensors for detection of lead(II) ion: a review. Anal Methods. 2017:9:1976-90

84. Zhang D, Yin L, Meng Z, Yu A, Guo L, Wang H. A sensitive fluorescence anisotropy method for detection of lead (II) ion by a G-quadruplexinducible DNA aptamer. Anal Chim Acta. 2014;812:161-7.

85. Wang Y, Lv M, Chen Z, Deng Z, Liu N, Fan J, et al. A fluorescence resonance energy transfer probe based on DNA-modified upconversion and gold nanoparticles for detection of lead ions. Front Chem. 2020;8:238.

86. Ouyang H, Ling S, Liang A, Jiang Z. A facile aptamer-regulating gold nanoplasmonic SERS detection strategy for trace lead ions. Sens Actuators, B Chem. 2018;258:739-44.

87. Tao Z, Zhou Y, Duan N, Wang Z. A colorimetric aptamer sensor based on the enhanced peroxidase activity of functionalized graphene $/ \mathrm{Fe}_{3} \mathrm{O}_{4}^{-}$ AuNPs for detection of lead (II) ions. Catalysts. 2020;10:600.

88. Wu Y, Shi Y, Deng S, Wu C, Deng R, He G, et al. Metal-induced G-quadruplex polymorphism for ratiometric and label-free detection of lead pollution in tea. Food Chem. 2021;343:128425.
89. Ma L-H, Wang H-B, Fang B-Y, Tan F, Cao Y-C, Zhao Y-D. Visual detection of trace lead ion based on aptamer and silver staining nano-metal composite. Colloids Surf, B. 2018;162:415-9.

90. Ahmad N, Bhatnagar S, Ali SS, Dutta R. Phytofabrication of bioinduced silver nanoparticles for biomedical applications. Int J Nanomed. 2015;10:7019-30.

91. Yuan M, Song Z, Fei J, Wang X, Xu F, Cao H, et al. Aptasensor for lead(II) based on the use of a quartz crystal microbalance modified with gold nanoparticles. Microchim Acta. 2017;184:1397-403.

92. Yu L, Zhao H, Jing N, Shi X, Zhang Y, Ding C, et al. A supramolecular probe of cyanine dye for $\mathrm{Pb}^{2+}$ detection based on the recognition of a G-quadruplex from DNA duplexes. Anal Methods. 2020;12:1182-5.

93. Chung E, Gao R, Ko J, Choi N, Lim DW, Lee EK, et al. Trace analysis of mercury(II) ions using aptamer-modified Au/Ag core-shell nanoparticles and SERS spectroscopy in a microdroplet channel. Lab Chip. 2013;13:260-6.

94. Kosturko LD, Folzer C, Stewart RF. The crystal and molecular structure of a 2:1 complex of 1-methylthymine-mercury(II). Biochemistry. 1974;13:3949-52.

95. Qi Y, Xiu F-R, Yu G, Huang L, Li B. Simple and rapid chemiluminescence aptasensor for $\mathrm{Hg}^{2+}$ in contaminated samples: a new signal amplification mechanism. Biosens Bioelectron. 2017:87:439-46.

96. Qi Y, Ma J, Chen X, Xiu F, Chen Y, Lu Y. Practical aptamer-based assay of heavy metal mercury ion in contaminated environmental samples: convenience and sensitivity. Anal Bioanal Chem. 2020;412:439-48.

97. Wang C, Tang G, Tan H. Colorimetric determination of mercury(II) via the inhibition by ssDNA of the oxidase-like activity of a mixed valence state cerium-based metal-organic framework. Mikrochim Acta. 2018;185:475.

98. Wu Y, Yue Y, Deng S, He G, Gao H, Zhou M, et al. Ratiometric-enhanced G-quadruplex probes for amplified and mix-to-read detection of mercury pollution in aquatic products. J Agric Food Chem. 2020;68:12124-31.

99. Caglayan MO. Plasmon resonance-enhanced internal reflection ellipsometry for the trace detection of mercuric ion. Int J Environ Sci Technol. 2017;15:909-14.

100. Sun C, Sun R, Chen Y, Tong Y, Zhu J, Bai H, et al. Utilization of aptamerfunctionalized magnetic beads for highly accurate fluorescent detection of mercury (II) in environment and food. Sens Actuators, B Chem. 2018:255:775-80.

101. Shi Y, Li W, Feng X, Lin L, Nie P, Shi J, et al. Sensing of mercury ions in Porphyra by Copper @ Gold nanoclusters based ratiometric fluorescent aptasensor. Food Chem. 2021;344:128694.

102. Bhardiya SR, Asati A, Sheshma H, Rai A, Rai VK, Singh M. A novel bioconjugated reduced graphene oxide-based nanocomposite for sensitive electrochemical detection of cadmium in water. Sens Actuators, B. 2021;328:129019.

103. Hasan MN, Salman MS, Islam A, Znad H, Hasan MM. Sustainable composite sensor material for optical cadmium(II) monitoring and capturing from wastewater. Microchem J. 2021;161:105800.

104. Xue Y, Wang Y, Wang S, Yan M, Huang J, Yang X. Label-free and regenerable aptasensor for real-time detection of cadmium(II) by dual polarization interferometry. Anal Chem. 2020;92:10007-15.

105. Gan Y, Liang T, Hu Q, Zhong L, Wang X, Wan H, et al. In-situ detection of cadmium with aptamer functionalized gold nanoparticles based on smartphone-based colorimetric system. Talanta. 2020;208:120231.

106. Ahmad N, Bhatnagar S, Saxena R, lqbal D, Ghosh AK, Dutta R. Biosynthesis and characterization of gold nanoparticles: Kinetics, in vitro and in vivo study. Mater Sci Eng, C. 2017;78:553-64.

107. Zhu Y-F, Wang Y-S, Zhou B, Yu J-H, Peng L-L, Huang Y-Q, et al. A multifunctional fluorescent aptamer probe for highly sensitive and selective detection of cadmium(II). Anal Bioanal Chem. 2017:409:4951-8.

108. Zeng L, Gong J, Rong P, Liu C, Chen J. A portable and quantitative biosensor for cadmium detection using glucometer as the point-of-use device. Talanta. 2019;198:412-6.

109. Bacon JR, Butler OT, Cairns WRL, Cook JM, Davidson CM, Cavoura O, et al. Atomic spectrometry update-a review of advances in environmental analysis. J Anal At Spectrom. 2020;35:9-53.

110. Siddiqui MF, Khan ZA, Jeon H, Park S. SPE based soil processing and aptasensor integrated detection system for rapid on site screening of arsenic contamination in soil. Ecotoxicol Environ Saf. 2020;196:1 10559. 
111. Nguyen N, Park CY, Park JP, Kailasa SK, Park TJ. Synergistic molecular assembly of an aptamer and surfactant on gold nanoparticles for the colorimetric detection of trace levels of $\mathrm{As}^{3+}$ ions in real samples. New J Chem. 2018;42:11530-8.

112. Zeng L, Zhou D, Gong J, Liu C, Chen J. Highly sensitive aptasensor for trace arsenic(III) detection using DNAzyme as the biocatalytic amplifier. Anal Chem. 2019;91:1724-7.

113. Zhang Z, Lei K, Li C, Luo Y, Jiang Z. A new and facile nanosilver SPR colored method for ultratrace arsenic based on aptamer regulation of Au-doped carbon dot catalytic amplification. Spectrochim Acta Part A Mol Biomol Spectrosc. 2020;232:118174.

114. Li J, Xi H, Kong C, Liu Q, Chen Z. "Aggregation-to-deaggregation" colorimetric signal amplification strategy for $\mathrm{Ag}^{+}$detection at the femtomolar level with dark-field microscope observation. Anal Chem 2018;90:11723-7.

115. Khoshbin Z, Housaindokht MR, Verdian A, Bozorgmehr MR. Simultaneous detection and determination of mercury (II) and lead (II) ions through the achievement of novel functional nucleic acid-based biosensors. Biosens Bioelectron. 2018;116:130-47.

116. Khoshbin Z, Housaindokht MR, Verdian A. A low-cost paper-based aptasensor for simultaneous trace-level monitoring of mercury (II) and silver (I) ions. Anal Biochem. 2020;597:113689.

117. Lu Z, Wang P, Xiong W, Qi B, Shi R, Xiang D, et al. Simultaneous detection of mercury (II), lead (II) and silver (I) based on fluorescently labelled aptamer probes and graphene oxide. Environ Technol. 2020. https://doi.org/10.1080/09593330.2020.1721565.

118. Lu Z, Xiong W, Wang P, Li X, Zhai K, Shi R, et al. Simultaneous detection of lead (II) and mercury (II) ions using nucleic acid aptamer molecular beacons. Int J Environ Anal Chem. 2019. https://doi.org/10. 1080/03067319.2019.1691183.

119. Feng D, Li P, Tan X, Wu Y, Wei F, Du F, et al. Electrochemiluminescence aptasensor for multiple determination of $\mathrm{Hg}^{2+}$ and $\mathrm{Pb}^{2+}$ ions by using the MIL-53(Al)@CdTe-PEI modified electrode. Anal Chim Acta. 2020;1100:232-9.

120. Wang J, Wang J, Zhou P, Tao H, Wang X, Wu Y. Oligonucleotideinduced regulation of the oxidase-mimicking activity of octahedral $\mathrm{Mn}_{3} \mathrm{O}_{4}$ nanoparticles for colorimetric detection of heavy metals. Mikrochim Acta. 2020;187:99.

121. Li F, Yu Z, Han X, Lai RY. Electrochemical aptamer-based sensors for food and water analysis: a review. Anal Chim Acta. 2019;1051:1-23.

122. Shen Z, He L, Cao Y, Hong F, Zhang K, Hu F, et al. Multiplexed electrochemical aptasensor for antibiotics detection using metallicencoded apoferritin probes and double stirring bars-assisted target recycling for signal amplification. Talanta. 2019;197:491-9.

123. Zhu C, Liu D, Li Y, Ma S, Wang M, You T. Hairpin DNA assisted dualratiometric electrochemical aptasensor with high reliability and anti-interference ability for simultaneous detection of aflatoxin B1 and ochratoxin A. Biosens Bioelectron. 2021;174:112654.

124. Li Z, Mohamed MA, Mohan AMV, Zhu Z, Sharma V, Mishra GK, et al. Application of electrochemical aptasensors toward clinical diagnostics, food, and environmental monitoring: review. Sensors. 2019;19:5435

125. Sahai N, Ahmad N, Gogoi M. Nanoparticles based drug delivery for tissue regeneration using biodegradable scaffolds: a review. Curr Pathobiol Rep. 2018;6:219-24.

126. Nan M-N, Bi Y, Xue H-L, Long H-T, Xue S-L, Pu L-M, et al. Modification performance and electrochemical characteristics of different groups of modified aptamers applied for label-free electrochemical impedimetric sensors. Food Chem. 2021;337:127761.

127. Liu Y, Deng Y, Li T, Chen Z, Chen H, Li S, et al. Aptamer-based electrochemical biosensor for mercury ions detection using AuNPs-modified glass carbon electrode. J Biomed Nanotechnol. 2018;14:2156-61.

128. Si X, Tang S, Wang K, Zhou G, Xia J, Zhao Y, et al. Electrochemical amplification for $\mathrm{Hg}(\mathrm{II})$ quantification by anchoring an enzymatically extended aptamer. Anal Lett. 2019;52:2883-95.

129. Ahlawat J, Guillama Barroso G, Masoudi Asil S, Alvarado M, Armendariz I, Bernal J, et al. Nanocarriers as potential drug delivery candidates for overcoming the blood-brain barrier: challenges and possibilities. ACS Omega. 2020;5:12583-95.
130. Diaz-Amaya S, Lin L-K, DiNino RE, Ostos C, Stanciu LA. Inkjet printed electrochemical aptasensor for detection of $\mathrm{Hg}^{2+}$ in organic solvents. Electrochim Acta. 2019;316:33-42.

131. Khatoon A, Khan F, Ahmad N, Shaikh S, Rizvi SMD, Shakil S, et al. Silver nanoparticles from leaf extract of Mentha piperita: Eco-friendly synthesis and effect on acetylcholinesterase activity. Life Sci. 2018;209:430-4.

132. Yu SH, Lee C-S, Kim TH. Electrochemical detection of ultratrace lead ion through attaching and detaching DNA aptamer from electrochemically reduced graphene oxide electrode. Nanomaterials. 2019;9:817.

133. Ding J, Zhang D, Liu Y, Yu M, Zhan X, Zhang D, et al. An electrochemical aptasensor for detection of lead ions using a screen-printed carbon electrode modified with Au/polypyrrole composites and toluidine blue. Anal Methods. 2019;11:4274-9.

134. Tang W, Yu J, Wang Z, Jeerapan I, Yin L, Zhang F, et al. Label-free potentiometric aptasensing platform for the detection of $\mathrm{Pb}^{2+}$ based on guanine quadruplex structure. Anal Chim Acta. 2019;1078:53-9.

135. Jin H, Zhang D, Liu Y, Wei M. An electrochemical aptasensor for lead ion detection based on catalytic hairpin assembly and porous carbon supported platinum as signal amplification. RSC Adv. 2020;10:6647-53.

136. Wang X, Gao W, Yan W, Li P, Zou H, Wei Z, et al. A novel aptasensor based on graphene/graphite carbon nitride nanocomposites for cadmium detection with high selectivity and sensitivity. ACS Appl Nano Mater. 2018;1:2341-6.

137. Mushiana T, Mabuba N, Idris AO, Peleyeju GM, Orimolade BO, Nkosi $D$, et al. An aptasensor for arsenic on a carbon-gold bi-nanoparticle platform. Sens Bio-Sens Res. 2019;24:100280.

138. Yadav R, Kushwah V, Gaur MS, Bhadauria S, Berlina AN, Zherdev AV, et al. Electrochemical aptamer biosensor for $\mathrm{As}^{3+}$ based on apta deep trapped Ag-Au alloy nanoparticles-impregnated glassy carbon electrode. Int J Environ Anal Chem. 2019;100:623-34.

139. Gu H, Yang Y, Chen F, Liu T, Jin J, Pan Y, et al. Electrochemical detection of arsenic contamination based on hybridization chain reaction and RecJf exonuclease-mediated amplification. Chem Eng J. 2018;353:305-10.

140. Wu Y, Lai RY. Electrochemical gold(III) sensor with high sensitivity and tunable dynamic range. Anal Chem. 2016;88:2227-33.

141. Zhang Z, Ji H, Song Y, Zhang S, Wang M, Jia C, et al. Fe(III)-based metal-organic framework-derived core-shell nanostructure: sensitive electrochemical platform for high trace determination of heavy metal ions. Biosens Bioelectron. 2017;94:358-64.

142. Mayne L, Lin C-Y, Christie SDR, Siwy ZS, Platt M. The design and characterisation of multifunctional aptamer nanopore sensors. ACS Nano. 2018;12:4844-52

143. Abu-Ali H, Nabok A, Smith TJ. Development of novel and highly specific ssDNA-aptamer-based electrochemical biosensor for rapid detection of mercury (II) and lead (II) ions in water. Chemosensors. 2019;7:27.

144. Wu F, Wu Y, Niu Z, Vollmer F. Integrating a DNA strand displacement reaction with a whispering gallery mode sensor for label-free mercury (II) ion detection. Sensors. 2016;16:1197.

145. Wang C, Cui X, Li Y, Li H, Huang L, Bi J, et al. A label-free and portable graphene FET aptasensor for children blood lead detection. Sci Rep. 2016;6:21711.

146. Sharifi A, Hallaj R, Bahar S, Babamiri B. Indirect determination of mercury(II) by using magnetic nanoparticles, CdS quantum dots and mercury(II)-binding aptamers, and quantitation of released CdS by graphite furnace AAS. Mikrochim Acta. 2020;187:91.

147. Wang H, Liu Y, Liu G. Reusable resistive aptasensor for Pb(II) based on the $\mathrm{Pb}(\mathrm{II})$-induced despiralization of a DNA duplex and formation of a G-quadruplex. Mikrochim Acta. 2018;185:142.

148. Vu C-A, Chen W-Y. Predicting future prospects of aptamers in fieldeffect transistor biosensors. Molecules. 2020;25:680.

149. Nguyen DK, Jang CH. Label-free liquid crystal-based detection of As(III) ions using ssDNA as a recognition probe. Microchem J. 2020;156:104834.

150. Ertan T, Caglayan MO. An ellipsometric biosensor using aptamer for the detection of mercuric ions. Chem Pap. 2020;75:89-97. 
151. Chen T, Wang H, Wang Z, Tan M. Construction of time-resolved luminescence nanoprobe and its application in As(III) detection. Nanomaterials. 2020;10:551.

152. Liu C-W, Tsai T-C, Osawa M, Chang H-C, Yang R-J. Aptamer-based sensor for quantitative detection of mercury (II) ions by attenuated total reflection surface enhanced infrared absorption spectroscopy. Anal Chim Acta. 2018;1033:137-47.

153. Ehzari H, Safari M, Shahlaei M. A new sensing strategy based on thymine bases $-\mathrm{Hg}^{2+}$-methylene blue coordination on the electrospun
PES-QDs platform for detection of $\mathrm{Hg}^{2+}$ in fruit juice samples. J Iran Chem Soc. 2019;16:2269-79.

\section{Publisher's Note}

Springer Nature remains neutral with regard to jurisdictional claims in published maps and institutional affiliations.
Ready to submit your research? Choose BMC and benefit from:

- fast, convenient online submission

- thorough peer review by experienced researchers in your field

- rapid publication on acceptance

- support for research data, including large and complex data types

- gold Open Access which fosters wider collaboration and increased citations

- maximum visibility for your research: over $100 \mathrm{M}$ website views per year

At BMC, research is always in progress.

Learn more biomedcentral.com/submissions 